\author{
Aus dem Fachbereich Medizin \\ der Johann Wolfgang Goethe-Universität \\ Frankfurt am Main \\ betreut am \\ Zentrum der Kinder- und Jugendmedizin \\ Klinik für Kinder- und Jugendmedizin \\ Direktor: Prof. Dr. Thomas Klingebiel
}

\title{
Die Rolle von oxidativem Stress auf die Zellviabilität von epithelialen Lungenzellen bei Ataxia-teleangiectasia
}

\author{
Dissertation \\ zur Erlangung des Doktorgrades der Medizin \\ des Fachbereichs Medizin \\ der Johann Wolfgang Goethe-Universität \\ Frankfurt am Main
}

vorgelegt von

Natascha Kowalski

aus Seeheim-Jugenheim

Frankfurt am Main, 2021 
Dekan: Prof. Dr. Stefan Zeuzem

Referent: Prof. Dr. Ralf Schubert

Korreferent: Prof. Dr. Gernot Rohde

Tag der mündlichen Prüfung: 15.11.2021 


\section{Inhaltsverzeichnis}

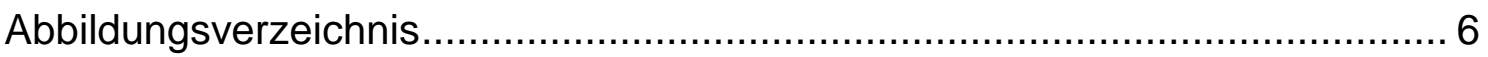

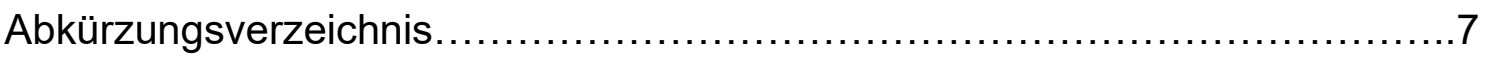

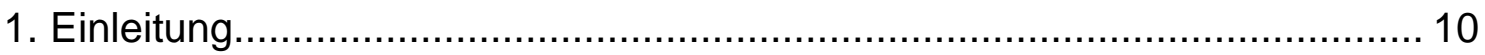

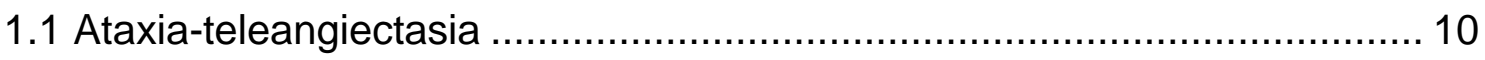

1.1.2 Die Lungenmanifestation bei A-T ............................................... 12

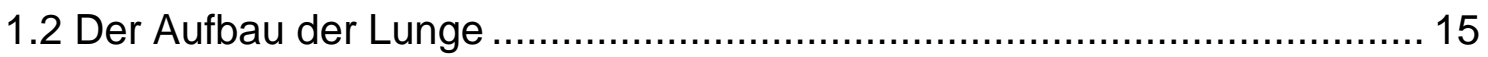

1.3 ATM, DNA-Doppelstrangbrüche und oxidativer Stress ............................ 17

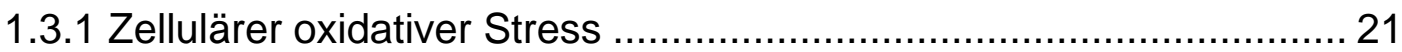

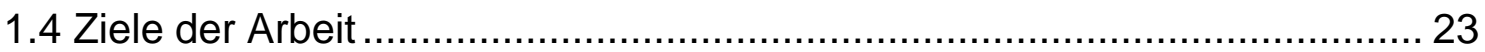

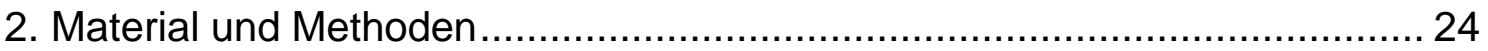

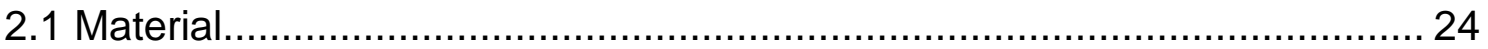

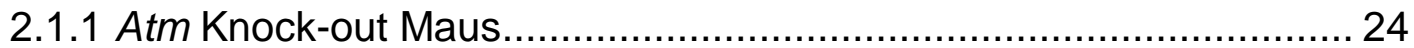

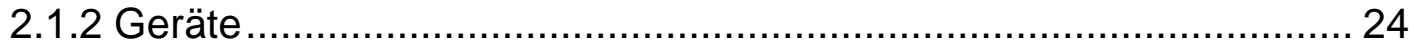

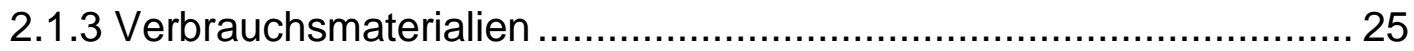

2.1.4 Chemikalien und Reagenzien ............................................... 26

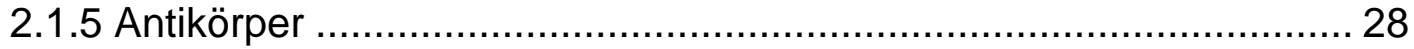

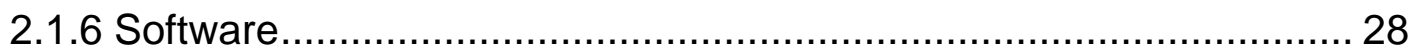

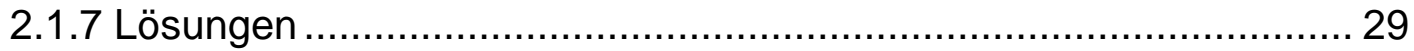

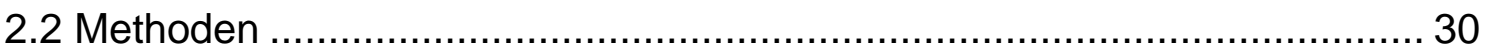

2.2.1 Grundlegende Techniken........................................................ 30 
2.2.1.1 Passagieren und Waschen von Zellen 30

2.2.1.2 Bestimmung der Zellzahl 30

2.2.2 Zellisolierung aus der murinen Lunge 30

2.2.2.1 Organentnahme und Zellisolierung mittels Agarose und Dispase . 30

2.2.2.2 Zellisolierung mittels Kollagenase. 31

2.2.4 Oberflächenfärbung und Durchflusszytometrie (FACS).... 32

2.2.5 Messung von ROS mittels DCF. 32

2.2.6 Färbung auf DNA-Schädigung mittels $\gamma \mathrm{H} 2 \mathrm{AX}$ 33

2.2.7 Zellproliferationsassay XTT 34

2.2.8 Statistik 34

3. Ergebnisse 35

3.1 Charakterisierung und Analyse pulmonaler Zellen Atm-defizienter und Wildtyp-Mäuse. 35

3.2 Analyse intrazellulärer ROS 36

3.3 Einfluss von Bleomycin auf intrazelluläre ROS und oxidativen Stress von Lungenzellen in vitro 37

3.4 Einfluss von oxidativem Stress auf die Populationen muriner Lungenzellen in vitro 38

3.5 Einfluss von Bleomycin auf die Viabilität Atm-defizienter Lungenzellen ..... 40 3.6 Einfluss von Bleomycin auf die DNA-Schädigung Atm-defizienter Zellen .. 42

4. Diskussion 44

5. Ausblick 55 
Inhaltsverzeichnis

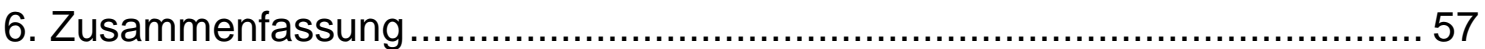

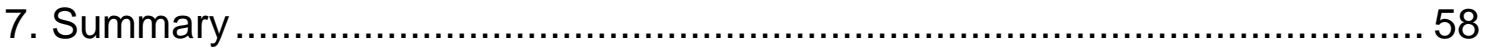

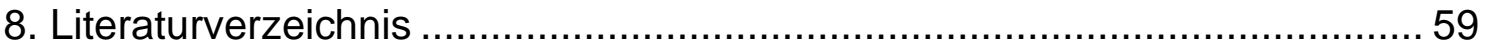

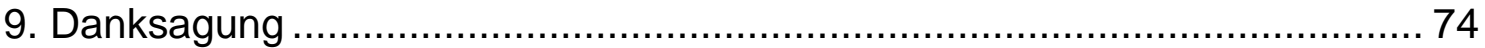

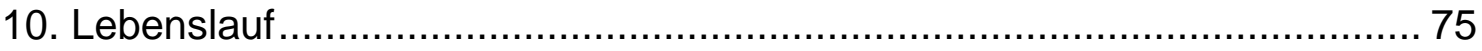

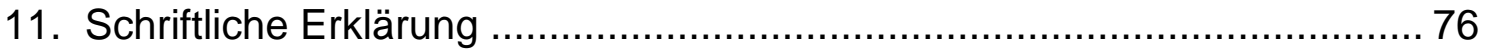




\section{Abbildungsverzeichnis}

Abbildung 1 Übersicht über die klinische Manifestation von A-T 11

Abbildung 2 Übersicht über die Zelltypen der Lunge und ihre Oberflächenmarker 16

Abbildung 3 Die Rolle von ATM 18

Abbildung 4 Oxidativer Stress in der Lunge, ein mehrstufiger Zyklus 22

Abbildung 5 Analyse primärer Lungenzellen Atm-defizienter und Wildtyp-Mäuse 36

Abbildung 6 Analyse reaktiver Sauerstoffspezies primärer muriner Lungenzellen Atm-defizienter und Wildtyp-Mäusen mittels Durchflusszytometrie 37

Abbildung 7 Der Effekt von BLM-induzierten oxidativen Stress auf die murinen Lungenzellen 38

Abbildung 8 Der Effekt von BLM auf Atm-defiziente AT2-Zellen 39

Abbildung 9 Der Effekt von BLM auf Atm-defiziente Fibroblasten 40

Abbildung 10 Der Effekt von Bleomycin auf die Zellviabilität muriner Lungenzellen in vitro. 41

Abbildung 11 Der Effekt von BLM auf murine Lungenzellen Atm-defizienter Mauszellen mittels Immunfluoreszenz dargestellt.

Abbildung 12 Resolution von DNA-Schäden anhand von $\gamma \mathrm{H} 2 \mathrm{AX}$ in Atm-defizienter und Wildtyp-Lungenzellen 


$\begin{array}{ll}\gamma \text { H2AX } & \text { Phosphoryliertes Histon 2AX } \\ \mu l & \text { Mikroliter } \\ \text { 8-OH-dG } & \text { 8-Hydroxy-Desoxyguanosin } \\ \text { APC } & \text { Allophycocyanin } \\ \text { A-T } & \text { Ataxia-teleangiectasia } \\ \text { AT1-Zellen } & \text { Alveolar Typ 1-Zellen (engl. alveolar epithelial cells type 1, AEC1) } \\ \text { AT2-Zellen } & \text { Alveolar Typ 2-Zellen (engl. alveolar epithelial cells type 2, AEC2) } \\ \text { ATM } & \text { Engl. Ataxia-teleangiectasia mutated } \\ \text { Atm }{ }^{-/} & \text {Atm-Knockout } \\ \text { Atm }{ }^{+/+} & \text {Atm-Wildtyp } \\ \text { AU } & \text { Engl. arbitrary unit } \\ \text { BADJ } & \text { Engl. bronchioalveolar duct junction, bronchoalveoläre Übergangszone } \\ \text { BASC } & \text { Engl. bronchioalveolar stem cells, alveoläre Vorläuferzelle } \\ \text { BLM } & \text { Bleomycin } \\ \text { BRCA1 } & \text { Engl. Breast Cancer 1 } \\ \text { c-Abl } & \text { Engl. Abelson murine leukemia viral oncogene homolog 1 } \\ \text { CD } & \text { Engl. Cluster of Differentiation } \\ \text { CF } & \text { Cystische Fibrose, engl. cystic fibrosis } \\ \text { DAPI } & \text { 4', 6-Diamidino-2-Phenylindoldihydrochlorid } \\ \text { DCF } & \text { 2',7'- dichlorofluorescein } \\ \text { DCF-DA } & \text { 2',7'- dichlorofluorescein diacetate } \\ \text { DDR } & \text { Engl. DNA damage response, DNA-Schaden-Reparatur } \\ \text { DMEM } & \text { Engl. Dulbecco's Modified Eagle Medium } \\ \text { DMSO } & \text { Dimethylsulfoxid } \\ \text { DNA } & \text { Engl. desoxyribonucleic acid, Desoxyribonukleinsäure } \\ \text { DNAse } & \text { Desoxyribonuklease } \\ \text { DSB } & \text { DNA-Doppelstrangbrüche } \\ \text { EDTA } & \text { Ethylendiamintetraessigsäure } \\ \text { EpCAM } & \text { Engl. epithelial cell adhesion molecule } \\ \text { et al. } & \text { Und andere } \\ \text { EtOH } & \text { Ethanol } \\ \text { EZM } & \text { Extrazelluläre Matrix } \\ \text { FACS } & \text { Engl. Fluorescence Activated Cell Sorting, Durchflusszytometrie } \\ \text { FC-Rezeptor } & \text { Engl. fragment crystallizable receptor } \\ & \end{array}$


FCS Engl. Fetal Calf Serum, fötales Kälberserum

FITC Engl. Fluorescein isothiocyanate

FSC Vorwärtsstreulicht

$\mathrm{H}_{2} \mathrm{O}_{2} \quad$ Wasserstoffperoxid

HBSS Engl. Hank's Balanced Salt Solutions

HEPES 2-(4-(2-Hydroxyethyl)-1-piperazinyl)-ethansulfonsäure

$\mathrm{HR}$

Homologe Rekombination

$\lg$

Immunglobulin

IL Interleukin

ILD Engl. interstitial lung disease, interstitielle Lungenerkrankung

kDA Kilodalton

MDC1 Engl. Mediator of DNA-damage checkpoint protein-1

MEM Engl. Nonessential Amino Acids

MFI

Mittlere Fluoreszenzintensität

Mre11

Engl. Meiotic recombination 11

MRN

Mre11-Rad50-Nbs1

$\mathrm{mU}$

Mili-Units

NBS

Nijmegen-Breakage-Syndrom

NEHJ

Engl. non-homologous end-joining, nichthomologe End-zu-EndVerknüpfung

$\mathrm{NF}$ B $\quad$ Engl. nuclear factor 'kappa-light-chain-enhancer' of activated B-cells

$\mathrm{nm}$

Nanometer

p53

Tumorsuppressor

PBS

Engl. Phosphate Buffered Saline

PE

Engl. Phycoerythrin

PerCP

Engl. Peridinin Chlorophyll Protein Complex

$p$-Wert

Lat. probabilitas, Wahrscheinlichkeit

RNS

Engl. reactive nitrogen species, reaktiven Stickstoffradikale

ROS

Engl. reactive oxygen species, reaktive Sauerstoffspezies

rpm

Engl. revolutions per minute

RSV

Engl. respiratory syncytial virus

Sca-1

Engl. Stem cells antigen-1

SEM

Engl. Standard Error of Measurement

SPC

Surfactant Protein C 
SSB

Engl. Single-Strand-Breaks, Einzelstrangbrüche

SSC

Seitwärtsstreulicht

TNF

Tumornekrosefaktor

XTT

Engl. cell proliferation assay 


\section{Einleitung}

\subsection{Ataxia-teleangiectasia}

Ataxia-teleangiectasia (A-T), auch unter dem Namen Louis-Bar-Syndrom bekannt, ist eine autosomal-rezessiv vererbte Erkrankung, welche mit einer durchschnittlichen Prävalenz von 1 zu 100.000 Lebendgeburten ${ }^{1}$ zu den sogenannten "orphan disease" zählt und sich bereits im frühen Kindesalter manifestiert. Aufgrund des progredienten Krankheitsverlaufs besteht derzeit eine Lebenserwartung von durchschnittlich 25 Jahren. ${ }^{2}$ Zum ersten Mal wurde die Multisystemerkrankung in den Jahren 1926 von Syballa und Henner und 1941 durch Denise Louis Bar beschrieben. ${ }^{3}$ Später wurde sie von Boder und Sedgwick weiter geprägt und als Erkrankung definiert. ${ }^{4}$ Ätiologisch liegt, der zur Gruppe der genomischen Instabilitätssyndrome zugehörigen Erkrankung, eine Mutation im sogenannten Ataxia-teleangiectasia mutated (ATM)-Gen zugrunde. Die aus dem Gen resultierende Proteinkinase ATM spielt eine zentrale Rolle in diversen zellulären Prozessen, unter anderem der Signaltransduktion, der ZellzyklusKontrolle und dem intrazellulären Transport. $^{5}$ Man unterscheidet zwei verschiedene Formen von A-T. Zum einen die klassische A-T, welche einen charakteristischen Verlauf mit klassischen Symptomen aufweist. Die am häufigsten vorkommenden Mutationsarten sind Nonsense-Mutationen durch Insertion oder Deletion, wodurch ein verkürztes, inaktives Protein entsteht. Im Gegensatz dazu manifestiert sich die milde „variante" Form der A-T häufig später, die Patient*innen ${ }^{a}$ weisen ein längeres Überleben auf und die Symptome können schwächer oder nur teilweise ausgeprägt sein. Ursächlich scheint hierfür eine residuale ATM-Kinaseaktivität $\mathrm{zu}$ sein, welche nur bei bestimmten Mutationsformen, wie beispielsweise Missense-Mutationen, entsteht. ${ }^{6-9}$ Klinisch präsentiert sich eine große und komplexe Bandbreite an Symptomen. Charakteristische Zeichen sind hierbei unter anderem eine progressive

a Aus Gründen der Lesbarkeit wird im Text ausschließlich die männliche Form gewählt. Nichtsdestoweniger beziehen sich die Angaben auf Angerhörige aller Geschlechter. 
zerebelläre Degeneration, Teleangiektasien, Immundefizienz mit Prädisposition für Tumorerkrankungen, erhöhte Strahlensensitivität und rezidivierende sinopulmonale Infektionen. Zusätzlich können Symptome wie Dystrophie, Gonadenatrophie mit verzögerter Pubertät oder ein insulinresistenter Diabetes mellitus vorkommen (Abbildung 1)..$^{10-13}$

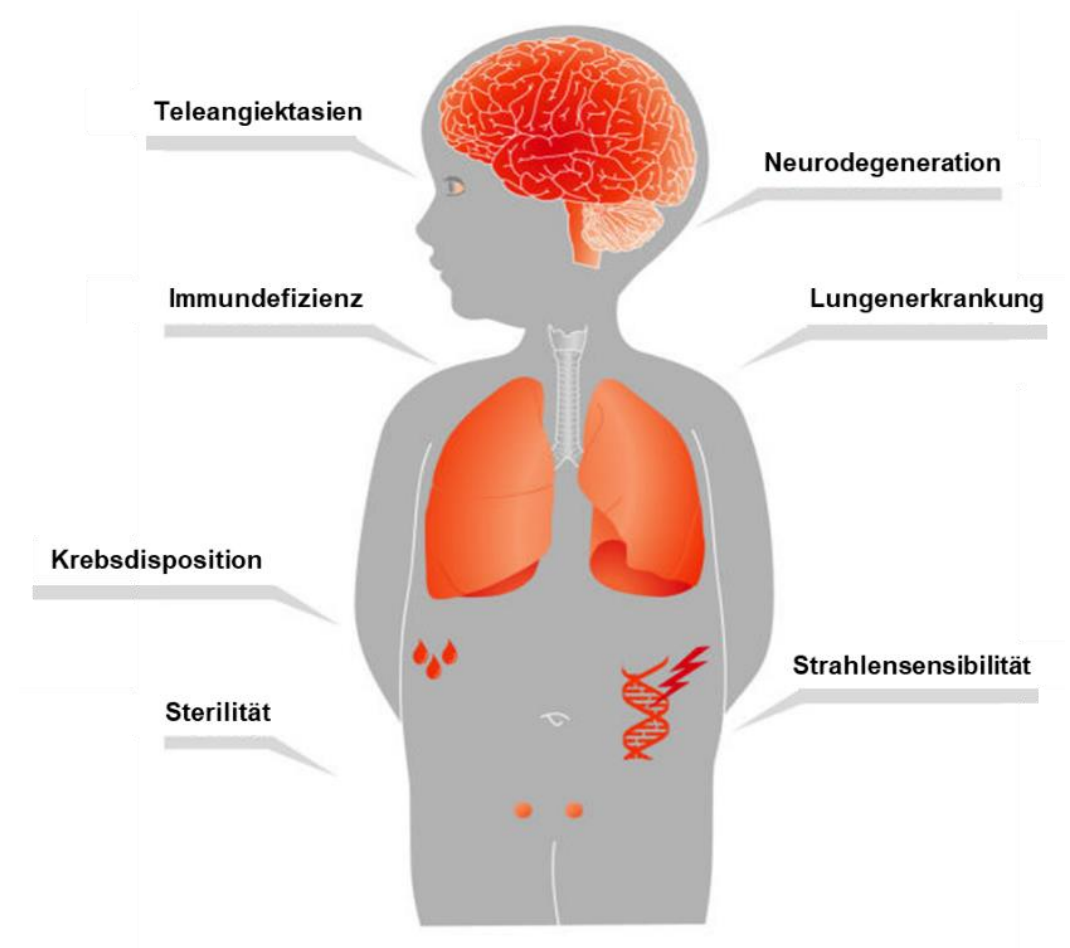

Abbildung 1 Übersicht der klinischen Manifestationen von A-T. Neben der Lungenerkrankung zählt auch die progressive Neurodegeneration zu den Merkmalen von A-T. Daneben sind Radiosensibilität, Immundefizienz und die Prädisposition für die Entstehung von Malignomen charakteristisch, modifiziert nach McKinnon et al. ${ }^{14}$

Laborchemisch fallen ein erhöhtes $\alpha$-Fetoprotein, eine Lymphopenie sowie niedrige Immunglobulinkonzentrationen im Serum auf. ${ }^{15,16}$ Die namensgebende Ataxie manifestiert sich meist als frühstes Symptom. Die frühkindliche neurologische Entwicklung der Kinder verläuft zunächst normal, mit der Zeit entwickelt sich dann eine ausgeprägte Ataxie mit charakteristischem "Clownsgang". Durchschnittlich sind die Kinder ab dem zehnten Lebensjahr auf einen Rollstuhl angewiesen und häufig treten feinmotorische Probleme, extrapyramidalmotorische Störungen sowie eine sensorische und motorische Neuropathie zu Tage. Die andere namensgebende Symptomatik sind irreversible, kapilläre Gefäßerweiterungen, die sogenannten Teleangiektasien. 
Diese manifestieren sich zumeist vier bis fünf Jahre nach dem ersten Auftreten der Ataxie und fallen typischerweise konjunktival, im Gesicht, den Ohren oder Händen auf, können aber auch komplett fehlen. ${ }^{17,18}$ Das zweite Hauptproblem ist die Immundefizienz. Etwa zwei Drittel der Patienten leiden an einem abnormen Immunsystem, wobei sowohl die zelluläre als auch die humorale Immunantwort betroffen ist. ${ }^{2,19}$ Die Inzidenz der Krebsentstehung ist mit etwa $25 \%$ erhöht und besonders häufig finden sich hämatopoetische Malignome wie Lymphome und Leukämien. ${ }^{20,21}$ Einzelne Fälle älterer A-T Patienten haben jedoch gezeigt, dass mit zunehmendem Alter die Inzidenz an soliden Tumoren ebenfalls stark zunimmt. ${ }^{21}$ Letztendlich zählen diese onkologischen Erkrankungen sowie die Lungenmanifestation mit progressivem Lungenversagen $z u$ den häufigsten Todesursachen bei A-T. 22-24 Derzeitige Therapieansätze sind rein symptomatischer Natur, eine kausale Therapie gibt es nicht. Die Diagnosestellung ist aufgrund der variablen Klinik mit unterschiedlicher Zusammensetzung und Schwere der Symptomatik schwierig. Die finale Diagnose erfolgt meist erst während des frühen Grundschulalters, wenn neurologische Symptome und Teleangiektasien auftreten oder progredient werden. Letztendlich stellt sie eine Kombination aus Klinik und laborchemischen Veränderungen dar. ${ }^{17,25,26} \mathrm{Zu}$ den wichtigsten differentialdiagnostischen Erwägungen zählen unter anderem die Ataxie mit okulomotorischer Apraxie Typ 1 und 2, die Friedreich Ataxie, die A-T-like disorder und die ebenfalls zu den genetischen Instabilitätssyndromen zugehörigen Erkrankungen Nijmegen-Breakage-Syndrom (NBS) und NBS-like disorder. Diese sind klinisch und laborchemisch von A-T zu unterscheiden. ${ }^{27,28}$

\subsubsection{Die Lungenmanifestation bei A-T}

Die Lungenschädigung bei A-T ist weit verbreitet und von großer prognostischer Bedeutung, da sie sowohl Einfluss auf die Morbidität als auch auf die Mortalität hat. Mit zunehmendem Alter steigt das Risiko eine Lungenschädigung zu entwickeln, sodass mehr als $70 \%$ der Erkrankten letztlich davon betroffen sind. ${ }^{24}$ Die Manifestation verläuft, wie die Erkrankung selbst, progredient und ein akutes oder chronisches Lungenversagen stellt eine der Haupttodesursachen dar. Aufgrund der eher unspezifischen Klinik werden die Symptome anfangs oft 
verkannt. Zu diesen zählen unter anderem chronischer Husten, Tachypnoe oder auch eine chronische Lungenüberblähung. ${ }^{23,27,29}$ Die pathophysiologischen Grundlagen der Lungenerkrankung bei A-T rückten in den letzten Jahren in den Fokus und sind dennoch noch nicht abschließend geklärt. Es wird vermutet, dass abnorme Reparationsvorgänge, vorzeitige Zellalterung, systemische Inflammation und oxidativer Stress zugrunde liegen. Diese Vorgänge spielen ebenfalls bei anderen Lungenerkrankungen, wie beispielsweise der Emphysementstehung, eine Rolle. ${ }^{29,30}$ Erhöhte Serumkonzentrationen proinflammatorischer Zytokine, wie Interleukin (IL)-6 und -8, sind bekanntermaßen charakteristisch für manche Erkrankungen mit Immundysregulation und spielen exemplarisch bei der rheumatoiden Arthritis auch therapeutisch eine Rolle. ${ }^{31,32}$ Zudem sind IL- 6 und -8 bei oxidativem Stress und Inflammation nachweislich erhöht. ${ }^{33}$ McGrath-Morrow et al. ${ }^{34,35}$ konnten in mehreren Studien belegen, dass jene Interleukine bei Patienten mit A-T ebenfalls erhöht sind und dies mit einer reduzierten Lungenfunktion einhergeht. Weiterhin gibt es Hinweise, dass eine erhöhte Serumkonzentration an IL-8 mit einem erhöhten Risiko für Krebsentstehung und Tod einhergeht. ${ }^{36}$

Die Lungenerkrankung präsentiert sich in verschiedenen Phänotypen. Vermutlich kommt es aufgrund des Immundefekts einerseits zu rezidivierenden Infekten der oberen und unteren Atemwege, wie Otitiden, Bronchitiden und Pneumonien. Dies fördert im Verlauf die Entstehung von sogenannten Bronchiektasien, welche etwa ab dem Ende der ersten Lebensdekade beobachtet werden können ${ }^{24,37}$ und sich aufgrund eines Circulus vitiosus, einer "tödlichen Spirale“, manifestieren. Infektionen und Inflammation schädigen dabei die Lungenarchitektur, führen zu einer Dilatation und verschlechtern eine zuvor bestehende Bronchiektasie. Hierdurch entstehen Symptome wie Husten, teilweise sogar mit Blutbeimengung (Hämoptyse), Kurzatmigkeit oder Gewichtsverlust. ${ }^{38}$ Zum anderen entwickeln sich aufgrund der neuromuskulären Degeneration Schluckstörungen mit einem ineffektiven Husten. Hierdurch potenziert sich das Risiko einer Aspiration und die Entstehung der Bronchiektasien wird zusätzlich forciert. ${ }^{39}$ Manche Patienten weisen außerdem eine interstitielle Lungenerkrankung (engl. interstitial lung disease, ILD) mit pulmonaler Fibrosierung und chronischer Inflammation auf. 
Ätiologie und Pathogenese dieser ILD sind weitgehend unbekannt und sie lässt sich in keine der von der American Thoracic Society und European Respiratory Society formulierten Kategorien der idiopathischen interstitiellen Pneumonien zuordnen. ${ }^{40}$ Für die Entstehung der Lungenerkrankung ist auch der Immundefekt bei A-T relevant. Bei etwa $10 \%$ der Betroffenen ${ }^{2}$ scheint eine lebensbedrohliche Immundefizienz zu existieren und aufgrund des Immunglobulinmangels, besonders von $\lg A, \lg G_{2}$ und $\lg G_{4}$, besteht eine reduzierte Antikörperreaktion nach Impfung, wodurch das Risiko für rezidivierende Infekte zusätzlich steigt. ${ }^{41,42}$ Besonders konventionelle Erreger fallen als Verursacher auf. Im frühen Kindesalter sind dies vor allem Viren, später werden sie durch bakterielle Erreger wie beispielsweise Staphylococcus aureus, Streptococcus pneumoniae und Haemophilus influenzae, ersetzt. Jene Bakterien zählen auch bei immunkompetenten Kindern und Jugendlichen zu den häufigsten Auslösern von Pneumonien. Mit zunehmendem Alter tritt dann eine vermehrte Kolonialisierung mit Pseudomonas aeruginosa auf, die häufig bei Patienten mit Cystischer Fibrose (engl. cystic fibrosis, CF) zu finden ist. Opportunistische Erreger spielen bei A-T, anders als bei anderen primären Immundefekten, keine große Rolle. 24,24,41,43,44 Wiederkehrende Infektionen scheinen bei A-T zudem einen schnelleren Abfall der pulmonalen Funktion, gemessen mittels Spirometrie, zufolge zu haben. ${ }^{45,46}$ Aufgrund dessen sollten die ersten klinischen Anzeichen gut beobachtet werden, damit gegebenenfalls mit Hilfe einer frühzeitig initiierten Therapie die Lungenfunktion lange aufrechterhalten werden kann. Da ausgedehnte Studien zum Thema Lungenmanifestation bei A-T fehlen, sind die Therapieregime rein symptomatischer Natur. Zur Reduktion der Morbidität sind frühzeitige Diagnostik und Therapie maßgebend. ${ }^{29}$

Diese pathophysiologischen Grundlagen finden sich jedoch nicht nur im Menschen. Das in dieser Arbeit verwendete Atm-defiziente Mausmodell wurde 1996 erstmalig von Barlow et al. ${ }^{10}$ beschrieben und spiegelt viele der phänotypischen Eigenschaften der A-T Patienten wider. So weisen die Mäuse unter anderem eine reduzierte Konzentration an Immunglobulinen mit Lymphopenie, einer genomischen Instabilität und erhöhten Strahlensensibilität auf. ${ }^{10}$ Weiterhin besteht bei Atm-defizienten murinen Zellen erhöhter oxidativer 
Stress $^{47}$ mit gesteigerter Konzentration an reaktive Sauerstoffspezies (engl. reactive oxygen species, ROS) und oxidativem Desoxyribonukleinsäure (engl. desoxyribonucleic acid, DNA)-Schaden. Durch den Gebrauch von Antioxidantien konnte dieser oxidative Stress und die daraus resultierende Schädigung reduziert und so die Lebenserwartung Atm-defizienter Mäuse verbessert werden. ${ }^{48,49}$ Als weiteren Hinweis für die Beteiligung inflammatorischer Prozesse konnten Eickmeier et al. ${ }^{50}$ anhand eines murinen Modells des akuten Lungenversagens deutlich machen, dass Atm-Defizienz eine erhöhte pulmonale Inflammation mit großem Gewebeschaden hervorruft. Aufgrund der bisherigen Erkenntnisse bietet das Atm-Mausmodell gute Möglichkeiten, die pathophysiologischen Grundlagen der Lungenerkrankung bei A-T zu studieren und ist somit für unsere Experimente gut geeignet.

\subsection{Der Aufbau der Lunge}

Die Atemwege werden in einen oberen und einen unteren Abschnitt eingeteilt und reichen vom Nasen-Rachenraum bis in die Lunge. Die Lunge selbst ist ein komplexes Organ, bestehend aus luftleitenden Bronchien und sogenannten respiratorischen Anteilen. Die für den Gasaustausch zuständigen Alveolen bilden dabei mit einer mittleren Anzahl von 300 - 400 Millionen den Großteil des Lungengewebes. Sowohl in der murinen als auch in der humanen Lunge verändern sich Typus und Anzahl der einzelnen Zellen von proximal nach distal, angepasst an die unterschiedlichen Bedürfnisse des jeweiligen Abschnittes (Abbildung 2). ${ }^{51,52,53}$ Proximal finden sich im murinen Atemwegsepithel multipotente Basalzellen, welche als Progenitorzellen dienen. Daneben sitzen schleimproduzierende sowie Zilien-tragende Zellen, die zur Reinigung Schmutz und Schleim aus der Lunge abtransportieren. Ein weiterer besonderer Typ sind die neuroendokrinen Zellen, die als Sensorzellen scheinbar mit dem Immun- und neuronalen System kommunizieren. ${ }^{54}$ Auf die Trachea und großen Bronchien folgen in der murinen Lunge sogenannte intermediäre oder terminale Bronchioli, welche durch eine Übergangszone (engl. bronchoalveolar duct junction, BADJ) mit den Alveolen verbunden sind. Hier befindet sich schlussendlich das für den eigentlichen Gasaustausch wichtige Alveolarepithel. Dieses besteht zum einen aus den an der Bildung der Blut-Luft-Schranke beteiligten Alveolar Typ 1 (AT1)- 
und zum anderen aus den Alveolar Typ 2 (AT2)-Zellen. ${ }^{55,56}$ AT1-Zellen kleiden mit ihrer flachen, länglichen Form über $95 \%{ }^{57}$ der inneren alveolären Oberfläche aus, sind aber mit etwa $8 \%{ }^{58}$ viel seltener als AT2-Zellen. Diese kuboidalen Zellen machen etwa $16 \%{ }^{58}$ der Gesamtzellzahl aus und produzieren das sogenannte Surfactant. Selbiges Protein setzt die Oberflächenspannung der Alveolen herab, um einen exspiratorischen Kollaps zu verhindern und die für die Inspiration benötigte Kraft zu reduzieren. ${ }^{59}$ Die Alveolen und ihre Zellen sind eingebettet in ein reichhaltiges Netz aus extrazellulärer Matrix (EZM), bestehend aus dichten Kollagen- und Elastinfasern sowie einer Vielzahl mesenchymaler Zellen, vor allem den Fibroblasten. ${ }^{60}$

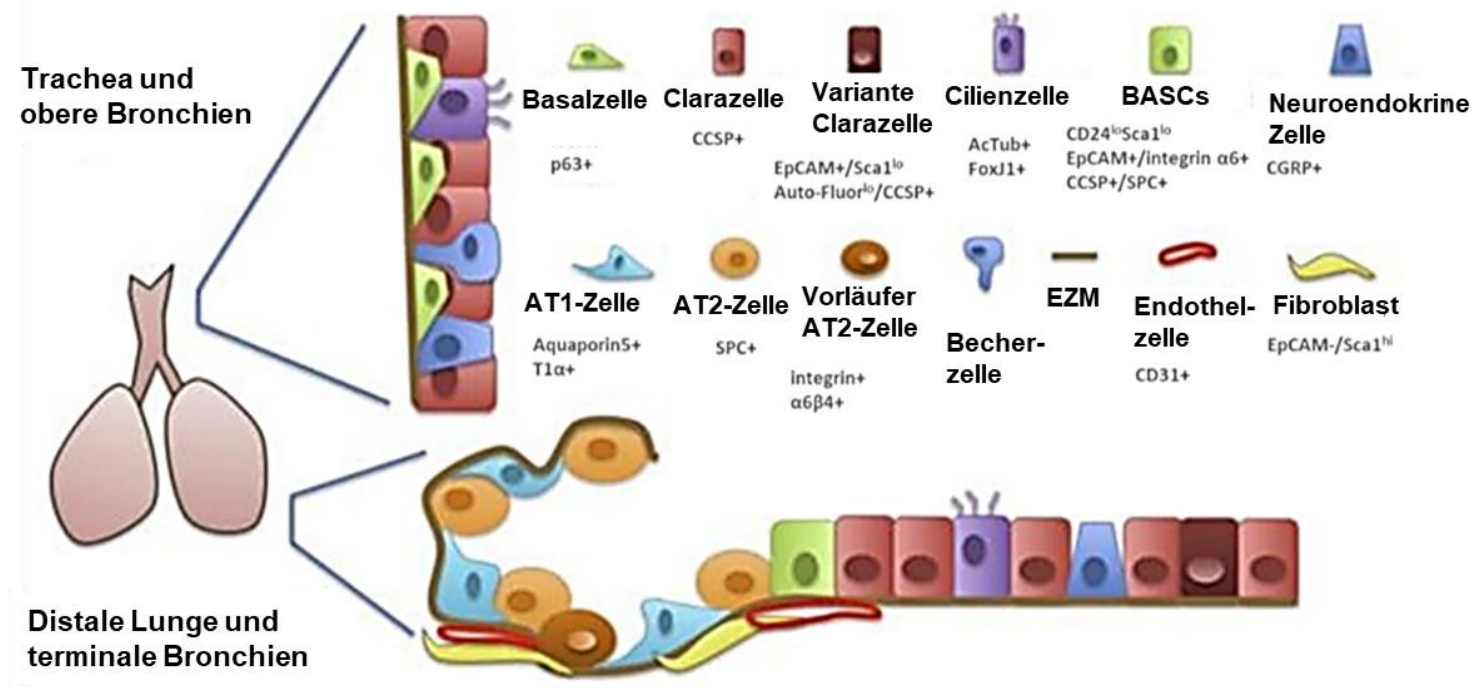

Abbildung 2 Übersicht der verschiedenen Zelltypen der Lunge und ihre Oberflächenmarker. In der murinen Trachea und den oberen Bronchien besteht das Epithel aus sekretorischen, ehemals Clara-Zellen genannt, und Zilien-tragenden Zellen. An der Basalmembran sitzen die sogenannten Basalzellen, welche sich wohl in Clara- sowie Zilienzellen differenzieren können. In distalen Regionen kommen zusätzlich auch neuroendokrine Zellen, sowie die AT1- und AT2-Zellen vor. Hier findet der eigentliche Gasaustausch statt. Zudem konnte eine alveoläre Vorläuferzelle (engl. bronchioalveolar stem cells, BASCs) identifiziert werden, welche sich vor allem am BADJ befinden. Eng neben den Alveolarepithelzellen findet man Zellen mesenchymalen Ursprungs, modifiziert nach Leeman et al.52

Die EZM ist nicht nur für den strukturellen Aufbau und die physiologischen Funktionen der Lunge notwendig, sondern unterstützt auch das Fortbestehen der alveolären Homöostase und des Signalmilieus. Mesenchymale Fibroblasten sind dicht neben den AT2-Zellen lokalisiert und fördern durch ihre parakrine Funktion deren Selbsterneuerung und Differenzierung. ${ }^{53,56}$ Während der physiologischen 
Homöostase unterliegt das Lungengewebe einer geringen zellulären Umsatzrate. In Kombination mit der zellulären Komplexität macht dies das Verständnis der zugrundeliegenden Mechanismen von Regeneration und Reparatur zu einer großen Herausforderung. ${ }^{54,61} \mathrm{Im}$ Anschluss an eine effektive Reparatur kann neben der Struktur auch die Funktion des Gewebes wiederhergestellt werden. ${ }^{62}$ Nach Teilentfernung eines Lungenflügels kann die murine Lunge das Gewebe innerhalb von etwa zwei Wochen ersetzen. ${ }^{63}$ Für die menschliche Lunge gilt dies nicht, da sie nur eine limitierte Kapazität besitzt, geschädigtes Lungengewebe wiederherzustellen. Zudem sinkt diese Kapazität mit zunehmendem Alter und eine vollständige Wiederherstellung von funktionellem Lungengewebe ist sehr selten. ${ }^{64,65}$ Die optimale Heilungsform bezeichnet die vollkommene Wiederherstellung der zellulären Integrität und Funktion (Restitutio ad integrum). Bei ausbleibender vollständiger Regenerationskapazität kommt es hingegen zu Reparaturmechanismen, welche unter anderem abnorme Gewebe- und Narbenbildung beinhalten und in manchen Fällen mit einem Funktionsverlust einhergehen. Regeneration und Reparatur treten häufig simultan auf und garantieren die strukturelle Integrität der Lunge ${ }^{56}$ und sind Aufgabe endogener Stamm- und Vorläuferzellen der Lunge. ${ }^{66} \mathrm{Im}$ Gegensatz zum hämatopoetischen System scheint es in der Lunge aber nicht nur eine ursprüngliche Zelle zu geben, sondern verschiedene, die für einzelne Regionen spezifisch sind. Neben ihrer sekretorischen Aktivität sind auch AT2-Zellen wichtige Stammzellen, die sich im Zuge des normalen Zellumsatzes oder nach Schädigung selbsterneuern sowie in AT1-Zellen differenzieren können. Dies konnte vor allem nach BLM-induziertem Lungenschaden gesehen werden. $55,61,67,68$

\subsection{ATM, DNA-Doppelstrangbrüche und oxidativer Stress}

Das ATM-Gen liegt auf Chromosom 11q22.23 und gehört zur Familie der Phosphatidylinositol-3-Kinase-ähnlichen Kinasen. Das resultierende, gleichnamige Protein ATM ist $370 \mathrm{kDa}$ schwer und besteht aus 3056 Aminosäuren. 1995 gelang es Savitsky et al. ${ }^{69}$ erstmals das ATM-Gen zu klonen und aktuell sind knapp 400 verschiedene Mutationen bekannt. Als Serin/Threonin-Kinase phosphoryliert ATM nach Aktivierung eine Vielzahl von 
Proteinen, die wichtige Funktionen in DNA-Doppelstrang-Reparaturprozessen, zellulärer Stressantwort und Zell-Zyklus-Kontrolle einnehmen. Zu diesen Targetproteinen gehören unter anderem p53, c-Abl und BRCA1, die allseits als wichtige Regulatorproteine für diverse zelluläre Prozesse gelten. Nach derzeitigem Stand sind noch nicht alle Funktionen des ATM-Gens geklärt, da eine Interaktion mit über 700 Proteinen bekannt ist. ATM wird in den Zellen des Körpers ubiquitär exprimiert. Dieses omnipräsente Vorkommen unterstreicht die herausragende Rolle von ATM für die Signaltransduktion und Kontrolle des Zellzyklus (Abbildung 3). ${ }^{70-72}$

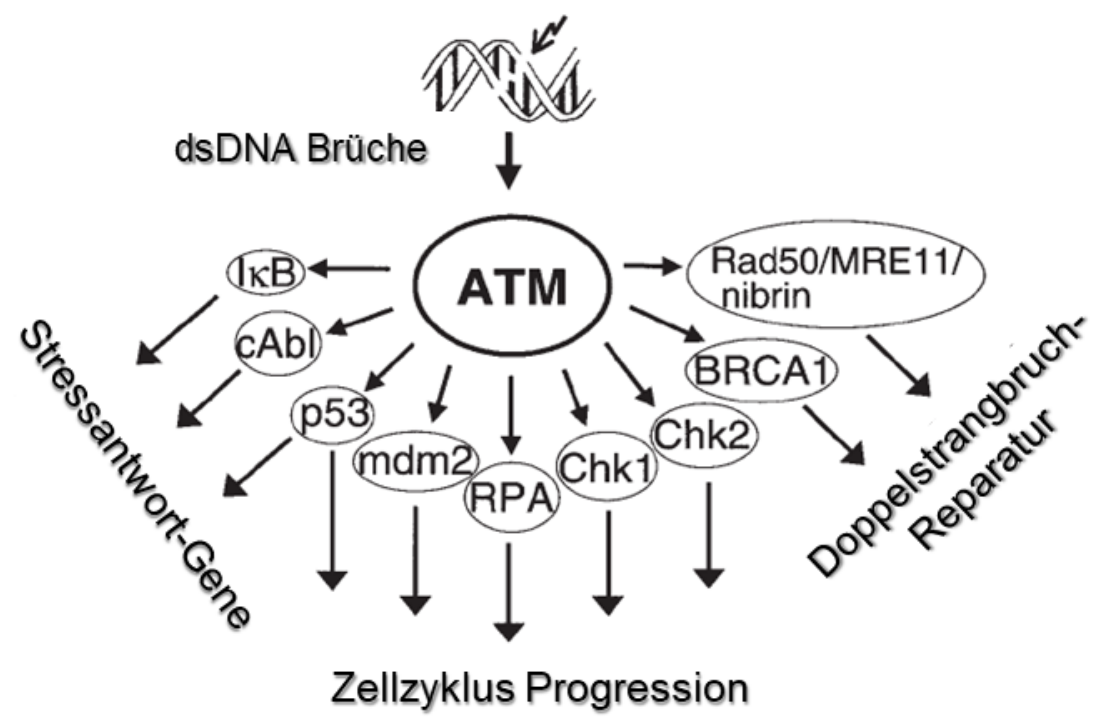

Abbildung 3 Die Rolle von ATM. ATM phosphoryliert nach Aktivierung eine Reihe von Proteinen, wodurch diverse intrazelluläre Reaktionsprozesse auf Stress und DNADoppelstrangbrüche aktiviert werden. $\mathrm{ds}=$ Doppelstrang, $\mid \varkappa \mathrm{B}=$ Enzymkomplex, $\mathrm{mdm} 2=$ mouse double minute 2 homolog, RPA = Replication Protein A, Chk1/2 = Checkpoint-Kinase 1/2, modifiziert nach Gatti et al. ${ }^{5}$

Die menschliche Zelle repräsentiert die kleinste Einheit des Körpers und erfüllt dabei alle wichtigen Grundfunktionen wie Stoffwechsel, Bewegung, Wachstum und Vererbung. Der Zellkern enthält das Chromatin mit der DNA, in welcher die erbliche Information der Zelle verschlüsselt ist. ${ }^{73}$ Die Integrität des Genoms ist dabei grundlegend für alle lebenden Organismen. Sowohl im Zuge normaler metabolischer Prozesse als auch durch schädliche Umweltfaktoren können verschiedene DNA-Schäden auftreten. Jede menschliche Zelle ist diesen individuellen Läsionen über 1 Millionen $\mathrm{Mal}$ pro Tag ausgesetzt. ${ }^{74}$ 
Die adäquate Reparatur dieser DNA-Schäden (engl. DNA damage response, DDR) ist essenziell für die zelluläre Homöostase und die Prävention der Kanzerogenese. Verschiedene Reparaturmechanismen konnten sogar bereits bei Prokaryoten entdeckt werden. ${ }^{75,76}$ Ist die DNA-Reparatur defekt entstehen Erkrankungen, die man als genomische Instabilitätssyndrome bezeichnet. Sie sind durch chromosomale Instabilität, erhöhte Sensitivität für Doppelstrangbrüche-induzierende Reagenzien sowie erhöhte Krebsdisposition gekennzeichnet. ${ }^{77,78}$ Eine der Hauptursachen für die Aktivierung des im Zellkern lokalisierten ATM sind DNA-Doppelstrangbrüche (DSB), welche die Integrität des Genoms stören. Die daraus resultierenden chromosomalen Aberrationen können zu einem zellulären Funktionsverlust führen, was schlussendlich im Zelltod enden kann. DSB sind jedoch nicht immer pathologisch, sondern auch Bestandteil normaler zellulärer Prozesse, wie der meiotischen Teilung, der Entwicklung des Immunsystems oder während der DNA-Replikation. ${ }^{77,79,80} \mathrm{Sie}$ entstehen einerseits durch exogene Reize wie beispielsweise ionisierende Strahlung oder Chemikalien. Zum anderen fallen sie endogen durch intrazellulär entstehende Stoffwechselprodukte wie ROS an. ${ }^{79}$ Eines dieser Chemikalien ist Bleomycin (BLM), ein aus Streptomyces verticillatus isoliertes, zytotoxisches Glykopeptid-Antibiotikum, das vor allem als Chemotherapeutikum Anwendung findet. 1962 erstmals entdeckt, entfaltet es seine zytotoxische Wirkung zum einen durch Störung der Replikation mittels Integration in die DNA und andererseits durch die Induktion von DSB und Einzelstrangbrüchen (engl. Single-StrandBreaks, SSB). Möglich ist dies durch seinen strukturellen Aufbau, bestehend aus vier verschiedenen Regionen mit spezialisierten Aufgaben. In Gegenwart von Sauerstoff und Metallionen wird BLM aktiviert und es entstehen ROS sowie reaktive Stickstoffradikale (engl. reactive nitrogen species, RNS). In höheren Konzentrationen inhibiert BLM zudem die RNA- und Proteinbiosynthese..$^{81,82}$ Treten DSB auf, so gibt es zwei verschiedene Reparaturwege. Zum einen durch homologe Rekombination (HR), zum anderen durch sogenannte nichthomologe End-zu-End-Verknüpfung (engl. non-homologous end-joining, NEHJ). Beide Wege werden durch unterschiedliche Proteine initiiert und sind hochkonservierte Prozesse. ${ }^{77,79,80}$ Bei der NEHJ werden die durch DSB getrennten Enden direkt wieder verbunden. Folglich ist dieser Prozess schnell, jedoch auch potenziell 
erbgutschädigend, da an den Bruchenden vor dem Zusammenfügen typischerweise wenige Nukleotide entfernt werden. Die HR ist langsamer, jedoch in ihrer Ausführung präziser. Zur Reparatur der DSB benötigt die HR eine homologe Sequenz als Vorlage, wofür meist das Schwesterchromatid verwendet wird. Das Vorliegen eines solchen Schwesterchromatid, was während des Zellzyklus nur in der S- und G2-Phase der Fall ist, stellt eine weitere Limitation dar. ${ }^{83}$ Nach DSB werden über ein noch unbekanntes Signal verschiedene Proteinkinasen aktiviert, die als Signalumwandler dienen und diverse Targetproteine sowie weitere Enzyme aktivieren, um DNA-Reparaturprozesse zu initiieren. Einer dieser wichtigen Signalumwandler ist ATM, wobei die genaue Rekrutierung und Aktivierung von ATM sehr komplex ist. Ein wesentlicher Aktivator ist der DNA-Reparaturkomplex Mre11-Rad50-Nbs1 (MRN), welcher als Sensor für DSB fungiert und diverse Proteine an die Bruchstelle rekrutiert. ATM bindet an den entstandenen MRN-Komplex und wird so aktiviert. ${ }^{14,84,85}$ Bakkenist und Kastan et al. ${ }^{86}$ fanden zudem heraus, dass ATM in nicht geschädigten Zellen als inaktives Dimer vorliegt. Werden DSB detektiert, sind die beiden Moleküle des Dimers in der Lage, sich mittels ihrer Kinasedomäne selbst durch Autophosphorylierung zu aktivieren. Die zwei entstehenden, aktiven Monomere können anschließend die Targetproteine von ATM aktivieren und den Zellzyklus, die DDR und gegebenenfalls die Apoptose-Mechanismen initiieren und regulieren. ${ }^{86,87}$ Neben der Regulation des Zellzyklus und der DNA-Reparatur ist die Modifikation des sogenannten H2AX eine weitere Maßnahme von ATM. ${ }^{79} \mathrm{Im}$ Zellkern wird die DNA durch basische Zellproteine, Histone genannt, aufgewickelt und stabilisiert. Eine wichtige Variante dieser Histone ist das H2AX, ein Protein der heterogenen Histonfamilie 2A.88,89 Durch spezifische Phosphorylierung am Serin-139 entsteht phosphoryliertes $\mathrm{H} 2 \mathrm{AX}(\gamma \mathrm{H} 2 \mathrm{AX})$, welches der Zelle den entstandenen Schaden anzeigt, um anschließend weitere Reparaturproteine rekrutieren zu können. ${ }^{79,90}$ Neben ATM sind weitere, zur Familie der PIKK zählende, Enzyme wie die Ataxia-Telangiectasia- und Rad3abhängige Kinase oder DNA-abhängige Proteinkinase an der Reparatur von DNA-Schäden beteiligt. ${ }^{79}$ Die wichtige Rolle von ATM in der Reparatur von DSB und Regulation von ROS, welche im folgenden Abschnitt näher erläutert wird, 
erklärt die genomische Instabilität und erhöhte Strahlensensibilität der A-TPatienten. ${ }^{91}$

\subsubsection{Zellulärer oxidativer Stress}

Die Theorie, dass freie Radikale bei der Entstehung diverser Erkrankungen eine Rolle spielen, besteht seit mehreren Jahrzehnten. Evidenzen gibt es dabei vor allem bei der Entstehung von Krebs, neurodegenerativen Erkrankungen und dem Alterungsprozess. Hochenergetische Formen von Sauerstoff entstehen beispielsweise nach Strahlenexposition oder durch Oxidationsmittel..$^{92}$ Unter normalen Umständen unterliegt die Produktion endogener ROS einer strikten Regulation. So werden sie im Zuge alltäglicher metabolischer Prozesse wie der mitochondrialen Energiegewinnung gebildet und eine leichte bis moderate Konzentration an ROS und RNS ist bei verschiedenen Reaktionen, wie der Infektabwehr, essenziell. Oxidativer Stress resultiert aus einer Dysbalance in der Entstehung und der Elimination von Sauerstoffradikalen durch das antioxidative System. ROS selbst sind instabile Moleküle mit ungepaarten Elektronen, die andere Moleküle oxidieren können. Hierzu zählen beispielsweise HyperoxidAnionen oder Hydroxyl-Radikale. ${ }^{93}$ Sie induzieren DNA-Schäden unter anderem in Form von SSB, DSB oder Basenmodifikationen. Über die Jahre hat das zelluläre System verschiedene Abwehrmechanismen gegen oxidativen Schaden entwickelt. Mit Hilfe von Antioxidantien, wie Vitamin C oder Glutathion, sowie diversen Enzymen, beispielsweise der Superoxid-Dismutase, werden lebensbedrohliche Schäden verhindert. Sollten diese Mechanismen trotzdem versagen, dient der programmierte Zelltod als letzter Ausweg. ${ }^{94,95}$ Die wichtigste Rolle der Lunge ist es, den Körper adäquat mit Sauerstoff zu versorgen und mit ihrer großen Oberfläche ist sie dafür bestens geeignet. Gleichzeitig macht sie dies auch anfällig für Verletzungen. Inhalative Oxidationsmittel in der Atemluft, etwa Stickstoffdioxid oder Abgase, induzieren oxidativen Stress und lösen eine Vielzahl von pathologischen Mechanismen in der Lunge aus (Abbildung 4). ${ }^{95}$ 


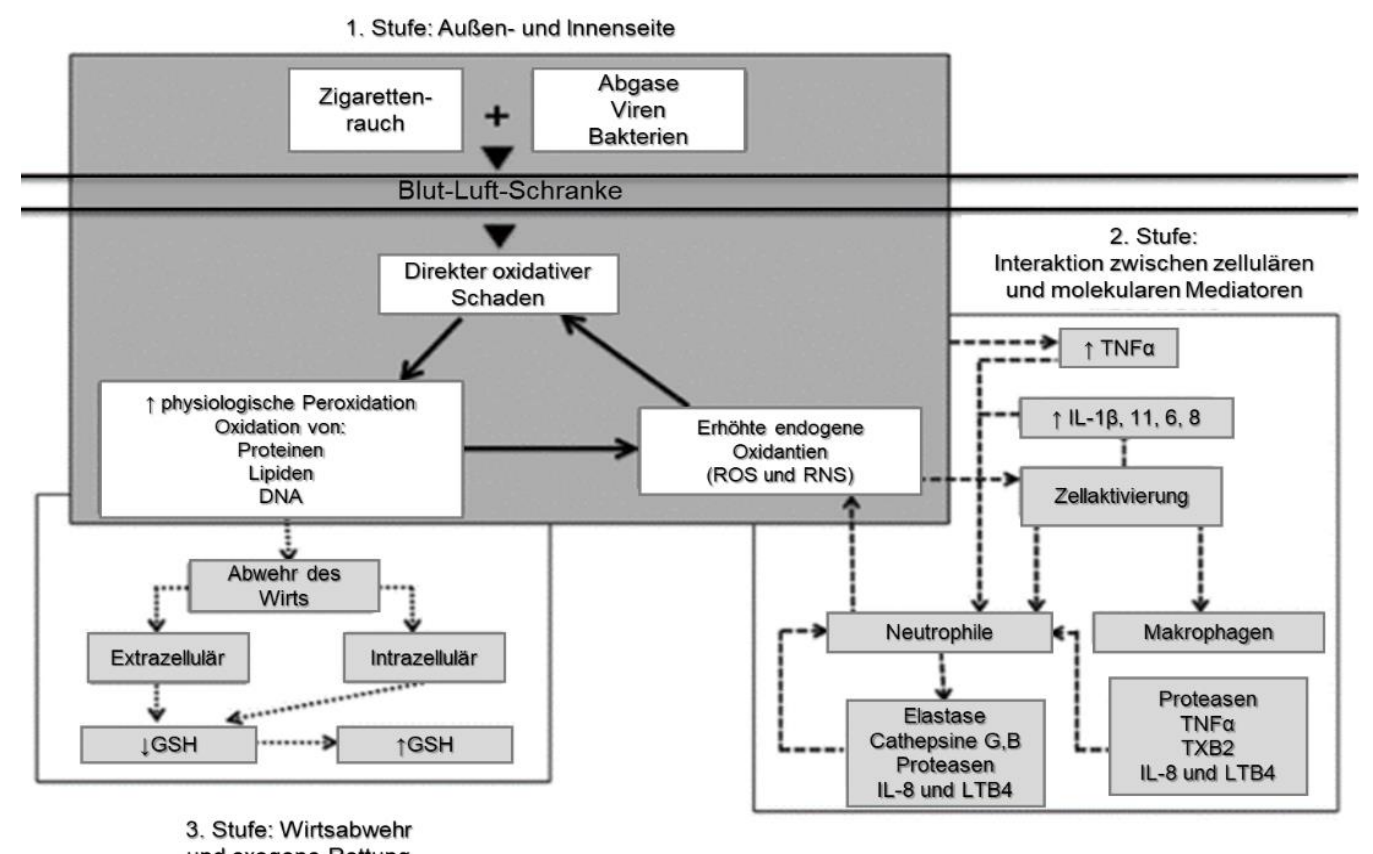

Abbildung 4 Oxidativer Stress in der Lunge, ein mehrstufiger Zyklus. Stufe 1: Durch endogene und exogene Trigger kommt es zu einer erhöhten Konzentration an ROS und RNS sowie zur Schädigung von Proteinen, Lipiden und DNA in der Zelle. Stufe 2: Auf zellulärer Ebene werden Neutrophile und Makrophagen angelockt, welche durch die Freisetzung von Zytokinen und Chemokinen eine inflammatorische Antwort triggern und zudem weitere Zellen anlocken. Dies potenziert die Inflammation zusätzlich. Stufe 3: Das antioxidative-System versucht die Konzentration an freien Radikalen zu senken und bereits hervorgerufene Schädigung zu beheben. LTB4 = Leukotrien B4, TXB2 = Thromboxan B2, GSH = reduziertes Glutathion, modifiziert nach Santus et al. ${ }^{95}$

In A-T weisen die Zellen neben DSB eine hohe Konzentration an ROS auf und sind sehr anfällig für oxidativen Stress beziehungsweise Reagenzien, die diesen auslösen. ${ }^{74}$ So konnten Guo et al. ${ }^{91}$ aufzeigen, dass ATM als wichtiger Sensor für ROS fungiert und durch Verschiebung des intrazellulären Redoxgleichgewichts aktiviert wird. Bei oxidativem Stress induziert durch die Zugabe von Wasserstoffperoxid $\left(\mathrm{H}_{2} \mathrm{O}_{2}\right)$, entsteht anders als nach DSB ein durch Disulfidbrücken verbundenes aktives ATM-Dimer. Eine vorherige Schädigung der DNA oder Aktivierung durch den MRN-Komplex ist dabei nicht nötig. ${ }^{91}$ Zusammenfassend stellt die Lunge ein sehr sensibles System dar, welches vor oxidativem Stress geschützt werden sollte. Durch wiederkehrende Infektionen sind gerade Patienten mit A-T oxidativem Stress und ROS in hohem Maße ausgesetzt. Umso wichtiger ist es, das Redoxsystem im Gleichgewicht zu halten, damit der erhöhten Anfälligkeit für Infektionen und Krebserkrankungen entgegengewirkt werden kann. ${ }^{96,97}$ 


\subsection{Ziele der Arbeit}

Die Lungenmanifestation bei A-T ist von großer prognostischer Bedeutung. Derzeit bestehen jedoch sowohl auf klinischer als auch auf pathophysiologischer Ebene offene Fragen hinsichtlich des Pathomechanismus. In dieser Arbeit wurden deshalb die pathophysiologischen Grundlagen, die zur Entstehung der Lungenschädigung bei A-T führen, näher untersucht. Da Patienten mit A-T durch wiederkehrende Infektionen in hohem Maße oxidativem Stress ausgesetzt sind, sollte der Effekt von ROS auf Atm-defiziente Lungenzellen im Vergleich zu Wildtyp-Zellen in vitro untersucht werden. Hierzu diente die inflammatorische und ROS-induzierende Eigenschaft von Bleomycin. Es sollte zunächst die Isolation primärer Lungenzellen aus Atm-defizienten und Wildtyp-Mäusen etabliert werden. Im nächsten Schritt sollte eine Charakterisierung der relevanten Lungenzelltypen Atm-defizienter und Wildtyp-Mäuse mittels Durchflusszytometrie erfolgen. Anhand von Viabilitäts- und oxidativen StressAssays sollte anschließend die Wirkung von Bleomycin als Auslöser von oxidativem Stress in Lungenzellen Atm-defizienter Mäuse im Vergleich zu Wildtyp-Mäusen untersucht werden. Die Induktion der DNA-Schädigung durch Bleomycin sollte mit Hilfe von $\gamma \mathrm{H} 2 \mathrm{AX}$ immunfluoreszenztechnisch und durchflusszytometrisch detektiert werden. Insgesamt sollte die erhöhte Anfälligkeit für oxidativen Stress und die reduzierte Reparationsfähigkeit ATMdefizienter Zellen nachgewiesen werden, um die pathophysiologischen Grundlagen dieser Erkrankung besser verstehen zu können. 


\section{Material und Methoden}

\subsection{Material}

\subsubsection{Atm Knock-out Maus}

Die für die Versuche verwendeten Mäuse wurden durch homologe Rekombination nach Barlow et al. ${ }^{10}$ durch das Labor von Dr. A Wynshaw-Boris generiert und der Arbeitsgruppe von Prof. Dr. R. Schubert zur Verfügung gestellt. Seit nun mehr 20 Jahren werden diese Mäuse in Frankfurt durch weitere Inzucht vermehrt.

\subsubsection{Geräte}

\begin{tabular}{l|l|l} 
Gerät & Typ & Hersteller \\
\hline Brutschrank & B 5060 BE-CO2 & $\begin{array}{l}\text { Heraeus, Hanau, } \\
\text { Deutschland }\end{array}$ \\
\hline Durchflusszytometer & FACSVerse & $\begin{array}{l}\text { BD-Bioscience, Heidelberg, } \\
\text { Deutschland }\end{array}$ \\
\hline Fluoreszenzmikroskop & $\begin{array}{l}\text { AxioPlan upright } \\
\text { Fluorescence } \\
\text { Microscope }\end{array}$ & $\begin{array}{l}\text { Carl Zeiss AG, Oberkochen, } \\
\text { Deutschland }\end{array}$ \\
\hline Fluoreszenzleser & FLUOstar ${ }^{\circledR}$ & $\begin{array}{l}\text { BMG Labtech, Ortenberg, } \\
\text { Deutschland }\end{array}$ \\
\hline $\begin{array}{l}\text { GentleMACS } \\
\text { Dissociator }\end{array}$ & $\begin{array}{l}\text { Miltenyi Biotec, Bergisch } \\
\text { Gladbach, Deutschland }\end{array}$ \\
\hline Heizblock & Thermomixer 5436 & $\begin{array}{l}\text { Eppendorf, Wesseling- } \\
\text { Berzdorf, Deutschland }\end{array}$ \\
\hline Kamera & Tucsen ISH 500 & Tucsen, Fijian, China \\
\hline Mikroskop & & $\begin{array}{l}\text { Olympus, Hamburg } \\
\text { Deutschland }\end{array}$ \\
\hline
\end{tabular}




\begin{tabular}{l|l|l} 
Gerät & Typ & Hersteller \\
\hline Spektrophotometer & Sunrise $^{\text {TM }}$ & Tecan, Männedorf, Schweiz \\
\hline Sterile Werkbank & Biosafe 2 & Ehret GmBH, Deutschland \\
\hline Vortexer & VortexGenie2 & $\begin{array}{l}\text { Scientific Industries, New } \\
\text { York, USA }\end{array}$ \\
\hline Feinwaage & Daeglef Platz KG & $\begin{array}{l}\text { Sartorius GmbH, Göttingen, } \\
\text { Deutschland }\end{array}$ \\
\hline Wasserbad & Varifuge 3.0 & $\begin{array}{l}\text { Heraeus, Hanau, } \\
\text { Deutschland }\end{array}$ \\
\hline Zentrifuge & &
\end{tabular}

\subsubsection{Verbrauchsmaterialien}

\begin{tabular}{l|l} 
Material & Hersteller \\
\hline Cryo Tubes & $\begin{array}{l}\text { Thermo Fischer Scientific, Roskilde, } \\
\text { Dänemark }\end{array}$ \\
\hline $\begin{array}{l}\text { Durchflusszytometrie- } \\
\text { Röhrchen }\end{array}$ & BD Bioscience, Heidelberg, Deutschland \\
\hline Falcon & Corning Incorporated, Lowell, USA \\
\hline Filter, $70 \mu \mathrm{m}$ & Corning Incorporated, Lowell, USA \\
\hline GentleMACS ${ }^{\text {TM }}$ C-Tubes & $\begin{array}{l}\text { Miltenyi Biotec, Bergisch Gladbach, } \\
\text { Deutschland }\end{array}$ \\
\hline Objektträger & $\begin{array}{l}\text { Thermo Scientific, Braunschweig, } \\
\text { Deutschland }\end{array}$ \\
\hline Pipet-Boy, Accu-jet-Pro & Brand, Wertheim, Deutschland \\
\hline Pipetten & Eppendorf, Wesseling-Berzdorf, Deutschland \\
\hline Spitzen & Eppendorf, Wesseling-Berzdorf, Deutschland
\end{tabular}




\begin{tabular}{l|l} 
Material & Hersteller \\
\hline Spritze & Fresenius Kabi, Bad Homburg, Deutschland \\
\hline Stripetten & Corning Incorporated, Lowell, USA \\
\hline Zählkammer, Neubauer & Optik Labor, Deutschland \\
\hline Zellkulturflaschen & Greiner bio-one, Frickenhausen, Deutschland \\
\hline Zellkulturschale & Sarstedt, Nürnbrecht, Deutschland \\
\hline $\begin{array}{l}\text { Zellkulturplatten } \\
\text { (6-, 24-, 96-Well) }\end{array}$ & Corning Incorporated, Lowell, USA
\end{tabular}

\subsubsection{Chemikalien und Reagenzien}

\begin{tabular}{|c|c|}
\hline Chemikalie & Hersteller \\
\hline 2-Mercaptoethanol & $\begin{array}{l}\text { Gibco by Life Technologies, Eggenstein, } \\
\text { Deutschland }\end{array}$ \\
\hline Accutase & Sigma Aldrich, Steinheim, Deutschland \\
\hline BD-FACS Lysing Solution & $\begin{array}{l}\text { BD Bioscience, Heidelberg, } \\
\text { Deutschland }\end{array}$ \\
\hline Bleocin $^{\mathrm{TM}}$ Calbiochem & Merck, Darmstadt, Deutschland \\
\hline DAPI, 4',6-Diamidin-2-phenylindol & $\begin{array}{l}\text { Thermo Scientific, Braunschweig, } \\
\text { Deutschland }\end{array}$ \\
\hline DCF, 2’,7`-di-chlorofluorescein & $\begin{array}{l}\text { Thermo Scientific, Braunschweig, } \\
\text { Deutschland }\end{array}$ \\
\hline Dispase & $\begin{array}{l}\text { BD Biosciences, Heidelberg, } \\
\text { Deutschland }\end{array}$ \\
\hline DMSO, Dimethylsulfoxid & Merck, Darmstadt, Deutschland \\
\hline $\begin{array}{l}\text { DMEM, Dulbecco's Modified } \\
\text { Eagle's medium }\end{array}$ & Invitrogen, Karlsruhe, Deutschland \\
\hline $\begin{array}{l}\text { DPBS, Dulbecco's Phosphate } \\
\text { Buffered Saline }\end{array}$ & $\begin{array}{l}\text { Gibco by Life Technologies, Eggenstein, } \\
\text { Deutschland }\end{array}$ \\
\hline EDTA, Ethylendiamintetraacetat & AppliChem, Darmstadt, Deutschland \\
\hline
\end{tabular}




\begin{tabular}{|c|c|}
\hline Chemikalie & Hersteller \\
\hline Ethanol $70 \%$ & Carl Roth, Karlsruhe, Deutschland \\
\hline Essigsäure & Sigma Aldrich, Steinheim, Deutschland \\
\hline FCS, Fetal Calf Serum & Sigma Aldrich, Steinheim, Deutschland \\
\hline Fixierungspuffer, BD Cytofix & $\begin{array}{l}\text { BD Pharmingen, Heidelberg, } \\
\text { Deutschland }\end{array}$ \\
\hline $\begin{array}{l}\text { HBSS, Hank's Balanced Salt } \\
\text { Solutions }\end{array}$ & Invitrogen, Karlsruhe, Deutschland \\
\hline $\mathrm{H}_{2} \mathrm{O}_{2}$ & $\begin{array}{l}\text { VWR International GmbH, Darmstadt, } \\
\text { Deutschlang }\end{array}$ \\
\hline Isofluran & Abbott GmbH, Wiesbaden, Deutschland \\
\hline Kollagenase & Sigma Aldrich, Steinheim, Deutschland \\
\hline Low Melt Agarose & Bio\&Sell, Nürnberg, Deutschland \\
\hline MEM Nonessential Amino Acids & $\begin{array}{l}\text { Gibco by Life Technologies, Eggenstein, } \\
\text { Deutschland }\end{array}$ \\
\hline Movicol 4-88 & Sigma-Aldrich, Steinheim, Deutschland \\
\hline Penicillin /Streptomycin & $\begin{array}{l}\text { Gibco by Life Technologies, Eggenstein, } \\
\text { Deutschland }\end{array}$ \\
\hline Trypanblau & Sigma-Aldrich, Steinheim, Deutschland \\
\hline Trypsin 0,25 \% & Invitrogen, Karlsruhe, Deutschland \\
\hline Trypsin $0,05 \%$ & Invitrogen, Karlsruhe, Deutschland \\
\hline XTT activation solution & $\begin{array}{l}\text { BD Bioscience, Heidelberg, } \\
\text { Deutschland }\end{array}$ \\
\hline XTT Reagenz & $\begin{array}{l}\text { BD Bioscience, Heidelberg, } \\
\text { Deutschland }\end{array}$ \\
\hline
\end{tabular}




\subsubsection{Antikörper}

\begin{tabular}{|c|c|c|c|c|c|}
\hline Methode & Antikörper & KIon & Isotyp & $\begin{array}{l}\text { Fluoro- } \\
\text { chrom }\end{array}$ & Hersteller \\
\hline \multirow{5}{*}{$\begin{array}{l}\text { Durchfluss- } \\
\text { zytometrie }\end{array}$} & CD16/32 & 93 & & Purified & Biolegend \\
\hline & $\begin{array}{l}\text { CD326 } \\
\text { (Ep-CAM) }\end{array}$ & G8.8 & $\begin{array}{l}\text { Ratte } \\
\text { lgG } 2 a, \kappa\end{array}$ & $\mathrm{Pe} / \mathrm{Cy} 7$ & $\begin{array}{l}\text { Miltenyi } \\
\text { Biotec }\end{array}$ \\
\hline & Sca-1 & D7 & $\begin{array}{l}\text { Ratte } \\
\text { lgG } G_{2 a, ~ \kappa}\end{array}$ & $\begin{array}{l}\text { PE, } \\
\text { FITC }\end{array}$ & $\begin{array}{l}\text { Miltenyi } \\
\text { Biotec }\end{array}$ \\
\hline & SPC & & $\begin{array}{l}\text { Kaninchen } \\
\lg G\end{array}$ & \begin{tabular}{|l|} 
Alexa \\
Fluor \\
647 \\
\end{tabular} & $\begin{array}{l}\text { Biossusa } \\
\text { Com. }\end{array}$ \\
\hline & $\begin{array}{l}\gamma \mathrm{H} 2 \mathrm{AX} \\
(\mathrm{pS} 139) \\
\end{array}$ & $\begin{array}{l}\text { N1- } \\
431\end{array}$ & \begin{tabular}{|l} 
Maus \\
$\lg G_{1}, \kappa$
\end{tabular} & $\begin{array}{l}\text { Alexa } \\
\text { Fluor } \\
647 \\
\end{array}$ & $\begin{array}{l}\text { BD } \\
\text { Pharmingen }\end{array}$ \\
\hline Immunfluoreszenz & $\begin{array}{l}\gamma \mathrm{H} 2 \mathrm{AX} \\
(\mathrm{pS} 139)\end{array}$ & $\begin{array}{l}\text { N1- } \\
431\end{array}$ & \begin{tabular}{|l} 
Maus \\
$\lg G_{1}, \kappa$
\end{tabular} & $\begin{array}{l}\text { Alexa } \\
\text { Fluor } \\
488\end{array}$ & $\begin{array}{l}\text { BD } \\
\text { Pharmingen }\end{array}$ \\
\hline
\end{tabular}

\subsubsection{Software}

Microsoft Office Word 2007, Microsoft Deutschland GmbH, Unterschleißheim

Microsoft Office Excel 2007, Microsoft Deutschland GmbH, Unterschleißheim

GraphPad Prism® 5, GraphPad Software, La Jolla, USA

FACSuite TM Software 6.0.6, BD Biosciences, San Jose, USA

FLUOstar Software, BMG Labtech, Ortenberg, Deutschland 


\subsubsection{Lösungen}

Kulturmedium für murine Lungenzellen

$20 \%$ FCS (hitzeinaktiviert für 30 min bei $56^{\circ} \mathrm{C}$ )

$1 \%$ MEM

$1 \%$ Penicillin /Streptomycin

1:500 2-Mercaptoethanol

mit DMEM (Versetzt mit L-Glutamat, Glucose und Pyruvat) auffüllen und steril filtrieren

DCF Stocklösung

0,1 mM DCF 1:10 mit PBS/1 mM EDTA verdünnen

XTT-Lösung

$0,1 \mathrm{ml}$ activation solution $+5 \mathrm{ml}$ XTT reagent

GentleMACS ${ }^{\mathrm{TM}}$ Puffer

5 ml DMEM

100 U/ml Penicillin

$100 \mu \mathrm{g} / \mathrm{ml}$ Streptomycin

2 mM Glutamin

20 mM HEPES

120 U DNAse 


\subsection{Methoden}

\subsubsection{Grundlegende Techniken}

\subsubsection{Passagieren und Waschen von Zellen}

Die Zellen wurden mit $1 \mathrm{ml}$ sterilem PBS gewaschen und mittels Trypsin-EDTA $0,25 \%$ für zwei bis fünf Minuten inkubiert. Anschließend wurde der Prozess mit der doppelten Menge Kulturmedium gestoppt und die Zellen mit 1800 rpm fünf Minuten bei $4{ }^{\circ} \mathrm{C}$ zentrifugiert. Der Überstand wurde verworfen und die Zellen konnten erneut kultiviert oder für Versuche verwendet werden.

\subsubsection{Bestimmung der Zellzahl}

Zur Bestimmung der Zellzahl wurden $10 \mu \mathrm{l}$ der Suspension mit $80 \mu \mathrm{l}$ Essigsäure (2\%) und $10 \mu \mathrm{l}$ Trypanblau suspendiert und auf eine Neubauerzählkammer gegeben. Trypanblau färbt selektiv tote Zellen, wodurch sich diese von lebenden Zellen abgrenzen lassen und Essigsäure lässt die Erythrozyten platzen, sodass die Lungenzellen besser erkannt und gezählt werden können.

Insgesamt wurden je vier Quadrate ausgezählt und der Mittelwert gebildet. Anschließend konnte die absolute Zellzahl mit folgender Formel berechnet werden:

Mittelwert x Verdünnung (1:10) x Kammerfaktor (10.000) x Volumen der Zellsuspension

\subsubsection{Zellisolierung aus der murinen Lunge}

\subsubsection{Organentnahme und Zellisolierung mittels Agarose und Dispase}

Es wurden murine Lungen von sechs bis neun Wochen alten Atm-defizienten und Wildtyp-Mäusen isoliert. Zur Tötung der Maus, welche von qualifizierten Mitarbeitern der AG Schubert durchgeführt wurde, verwendeten wir eine Überdosis Isofluran. Anschließend wurden Herz und Lunge nach Corti et al. ${ }^{98}$ sorgfältig frei präpariert. Mit Hilfe eines Butterflys wurde der rechte Herzventrikel punktiert und hierüber der Lungenkreislauf mit $20 \mathrm{ml}$ PBS gespült. 
Nach Freilegung der Trachea konnte über eine intratracheale Kanüle, 1,5 ml Dispase $\left(37^{\circ} \mathrm{C}\right)$ sowie $0,5 \mathrm{ml}$ einer 1 \%igen Low Melt Agarose, welche vor Verwendung bei $70^{\circ} \mathrm{C}$ im Thermomixer verflüssigt wurde, in die Lunge gegeben werden. Nach fünf-minütiger Einwirkzeit konnte die erhärtete Lunge entfernt und in $3 \mathrm{ml}$ Dispase bei Körpertemperatur transportiert werden.

Die Lungen wurden unter der sterilen Werkbank in ein C-Tube gefüllt mit $3 \mathrm{ml}$ GentleMACS Puffer überführt und anschließend mit Hilfe des GentleMACS Dissociator Programms m_lung_1.01 und_1.02 zerkleinert. Im Anschluss wurde die Suspension zunächst begutachtet. Falls noch größere Lungenreste vorhanden waren, wurde das Programm erneut verwendet. Das Röhrchen konnte bei $1800 \mathrm{rpm}$ für zehn Minuten bei $4^{\circ} \mathrm{C}$ zentrifugiert und der Überstand verworfen werden. Die Zellen wurden anschließend filtriert, in $4 \mathrm{ml}$ DMEM suspendiert und in ein Falcon-Röhrchen überführt. Die Zellzahl wurde mit der o.g. Methode bestimmt.

\subsubsection{Zellisolierung mittels Kollagenase}

Nach Tötung der Maus wie oben beschrieben, wurde die Lunge im Ganzen heraus präpariert und in ein Reaktionsgefäß mit $2 \mathrm{ml}$ HBSS überführt. Die anschließende Aufbereitung erfolgte nach dem Protokoll des Paul-EhrlichInstituts Langen, Deutschland, welches unserer Arbeitsgruppe freundlicherweise zur Verfügung gestellt wurde. Unter der sterilen Werkbank wurde die Lunge dann entweder mit Hilfe eines Skalpells zerschnitten oder in einem C-Tube mit Hilfe des GentleMACS zerkleinert. Nach Zugabe von 2 ml Kollagenase, wurde die Probe für 25 Minuten bei $37^{\circ} \mathrm{C}$ im Brutschrank inkubiert. Anschließend wurde bei $1200 \mathrm{rpm}$ zentrifugiert, vorsichtig dekantiert und der Überstand verworfen. Die Zellen wurden dann mit 1-3 ml HBSS gewaschen, resuspendiert und erneut zentrifugiert. Anschließend wurden die Zellen mit $2 \mathrm{ml}$ 0,05\%igem Trypsin suspendiert und erneut für 20 Minuten bei $37^{\circ} \mathrm{C}$ inkubiert. Nach abschließender Zentrifugation konnten die Zellen mit Kulturmedium resuspendiert werden, wobei durch mehrfaches Auf- und Abpipettieren größere Zellaggregate zu lösen waren. Anschließend wurde die Suspension in Zellkulturschalen ausgesät. Die Zellzahlbestimmung erfolgte nach der oben genannten Methode. 


\subsubsection{Oberflächenfärbung und Durchflusszytometrie (FACS)}

Anhand ihrer Oberflächenmarker lassen sich Zellen mit Hilfe der Durchflusszytometrie näher charakterisieren. Hierzu wurden die adhärenten Zellen zunächst dreimal mit sterilem PBS gewaschen und anschließend mit Accutase für fünf Minuten bei $37^{\circ} \mathrm{C}$ im Brustschrank inkubiert. Haben sich die Zellen ausreichend gelöst, wurde der Vorgang mit Kulturmedium gestoppt, die Suspension in FACS-Röhrchen überführt und bei 1200 rpm für fünf Minuten zentrifugiert. Die Zellzahl wurde auf 0,5 × $10^{6}$ Zellen pro Milliliter eingestellt. Nach einem erneuten Waschschritt mit PBS/1 mM EDTA erfolgte die Oberflächenfärbung.

Die Fc-Rezeptoren der Zellen wurden vor der eigentlichen Oberflächenfärbung mittels $1 \mu$ CD16/32 10 Minuten inkubiert und somit geblockt. Anschließend wurde $1 \mu \mathrm{l}$ des Antikörpers hinzugegeben und die Röhrchen für weitere 30 Minuten im Dunkeln bei Raumtemperatur inkubiert (Tab. unter 2.1.5.) Nach der Inkubation folgte ein Waschschritt mit PBS/1 mM EDTA. Nach Zentrifugation wurden die Zellen in $500 \mu \mathrm{l}$ PBS/1 mM EDTA aufgenommen und die Proben im Durchflusszytometer gemessen. Die Auswertung der Daten erfolgte mit Hilfe der FACSSuite Software.

\subsubsection{Messung von ROS mittels DCF}

Zur Analyse intrazellulärer reaktiver Sauerstoffspezies wurden zwei verschiedene Methoden verwendet. Nach Isolation wurden die primären Lungenzellen zur zusätzlichen Induktion von oxidativem Stress teilweise mit 10mU BLM für 24 Stunden inkubiert. Anschließend wurden die Zellen nach der oben beschriebenen Methode oberflächengefärbt und mit 0,05 $\mu \mathrm{M}$ DCF für 15 Minuten bei $37{ }^{\circ} \mathrm{C}$ im Brustschrank inkubiert, bevor sie mittels Durchflusszytometer analysiert wurden. Bei der zweiten Methode wurden die Lungenzellen nach Isolation zunächst auf einer 96-Well Platten ausgesät (20.000 Zellen pro Well) und unter Standardzellkulturbedingungen kultiviert. Ein Teil der Zellen wurde ebenfalls zusätzlich für 24 Stunden mit $10 \mathrm{mU}$ BLM stimuliert. Anschließend wurden die Zellen zweimalig mit $100 \mu \mathrm{l}$ HBSS gewaschen und vor 
der Messung mit $20 \mu \mathrm{M}$ DCF pro Well für 30 Minuten bei $37^{\circ} \mathrm{C}$ im Brutschrank inkubiert. Das nicht fluoreszierende 2',7' - dichlorofluorescein Diazetat (DCF-DA) diffundiert dabei in die Zelle und wird dort deazetyliert. Durch Oxidation entsteht das fluoreszierende DCF. Die Messung der Fluoreszenz erfolgte bei der zweiten Methode nach Hinzufügen weiterer $100 \mu \mathrm{l}$ HBSS pro Well unter Verwendung eines Fluoreszenz-Mikroplatten-Lesegeräts (FLUOstar ${ }^{\circledR}$ ) mit einer Einstellung der Emission/Absorption von $485 \mathrm{~nm} / 538 \mathrm{~nm}$. Die Auswertung der Daten erfolgte mit Hilfe der FLUOstar ${ }^{\circledR}$ Software und Excel.

\subsubsection{Färbung auf DNA-Schädigung mittels $\gamma \mathrm{H} 2 \mathrm{AX}$}

Zur Bestimmung der Expression von $\gamma \mathrm{H} 2 \mathrm{AX}$ wurden ebenfalls zwei verschiedene Methoden verwendet. Zum einen die Färbung und Analyse mittels Durchflusszytometrie, zum anderen die Immunfluoreszenzfärbung in einem Chamberslide. Die Färbung erfolgte nach einem modifizierten Protokoll von Tanaka et al. ${ }^{90}$. Für die durchflusszytometrische Analyse wurden die Zellen auf Well-Platten ausgesät und für 24 Stunden bzw. 3 Stunden mit 10 mU Bleomycin stimuliert. Anschließend wurden die Zellen wie oben bereits beschrieben mit Accutase vom Wellboden gelöst, mit PBS gewaschen und mit $100 \mu$ BD Cytofix fixation buffer 10 Minuten bei Raumtemperatur fixiert. Nach einem erneuten Waschschritt wurden die Zellen mit eiskaltem Methanol für 15-30 Minuten bei Raumtemperatur permeabilisiert. Nach zweimaligem Waschen erfolgte die Färbung von $\gamma \mathrm{H} 2 \mathrm{AX}$ mittels konjugierter Antikörper (siehe Tab. unter 2.1.5.) wie unter Punkt 2.2.4 beschrieben. Einziger Unterschied bestand in einer einstündigen Inkubation des anti- $\gamma \mathrm{H} 2 \mathrm{AX}$ Antikörper (Alexa Fluor 647 Mouse anti-H2AX pSer139) im Dunkeln. Die Auswertung erfolgte mittels FACSuite Software. Für die Immunfluoreszenzfärbung wurden nach Isolation 75.000 Zellen pro Well auf ein Chamberslide gegeben und mit mindestens $200 \mu$ Medium für 48 Stunden inkubiert. Anschließend erfolgte die Stimulation einzelner Slides mit 10 mU BLM für 24 Stunden. Die anschließende Fixierung, Permeabilisierung und Färbung erfolgte wie zur durchflusszytometrischen Analyse. Nach der einstündigen Inkubation im Dunkeln wurde der Überstand verworfen, die Zellen erneut gewaschen und die Nuklei abschließend mit DAPI (blau-fluoreszierende 
DNA-Färbung) gegengefärbt. Damit die Zellen unter dem Fluoreszenzmikroskop begutachtet werden konnten, wurde mit Hilfe von Movicol ein Deckglas auf dem Objektträger befestigt.

\subsubsection{Zellproliferationsassay XTT}

Das XTT stellt eine weit verbreitete Methode zur quantitativen Bestimmung von Zellproliferation dar. 0,25 × 105 Zellen (25.000) wurden nach Isolation auf eine 96-Well-Platte gegeben und mit $100 \mu$ Kulturmedium bedeckt. Die Zellen wurden dann mit $1 \mathrm{mU}, 5 \mathrm{mU}, 10 \mathrm{mU}$ und $20 \mathrm{mU}$ Bleomycin für 24 Stunden inkubiert. Zum Vergleich wurde 70 \%iges Ethanol als Positivkontrolle sowie eine unstimulierte Kontrolle verwendet. Am Tag der Messung wurden die Überstände abgenommen und die Zellen mit $100 \mu$ DMEM bedeckt. Als Hintergrundkontrolle, dem sogenannten blank, wurde $100 \mu$ PBS verwendet. Die Well wurden mit $50 \mu \mathrm{l}$ XTT Lösung (s.o.) bestückt und für drei Stunden bei $37^{\circ} \mathrm{C}$ in Brutschrank inkubiert. Anschließend erfolgte die Messung der Absorption mit dem Spektrophotometer bei $490 \mathrm{~nm}$.

\subsubsection{Statistik}

Die statistische Analyse der gewonnenen Daten erfolgte mittels ungepaarten t-Tests und 2-way-Anova Analysen. Zur Hilfe wurde die dabei die GraphPad Prism ${ }^{\circledR} 5$ Software benutzt. Alle Werte sind in Mittelwert \pm SEM angegeben und die Signifikanz wurde mit ${ }^{*} p<0,05,{ }^{* *} p<0,01$ und ${ }^{* *} p<0,001$ festgelegt. 


\section{Ergebnisse}

\subsection{Charakterisierung und Analyse pulmonaler Zellen Atm-defizienter und Wildtyp-Mäuse}

Die Lungenproblematik ist eine der Haupttodesursachen bei A-T und die pathophysiologischen Grundlagen sind bis heute noch nicht vollständig verstanden. Im Verlauf der Erkrankung kommt es zu rezidivierenden Entzündungen, Bildung von Bronchiektasien und fibrotischen Umwandlungen.28 Für diese Umwandlungsprozesse essenziell sind alveolare Epithelzellen sowie Fibroblasten, da sie nach Schädigung proliferieren und somit zur Fibrosierung der Lunge beitragen.59,99 Zur Untersuchung der Populationen Atm-defizienter muriner Lungen wurden die Zellen anhand ihrer Oberflächenmarker durchflusszytometrisch charakterisiert und mit den Zellen von Wildtyp-Mäusen verglichen. Nach Leeman et al. ${ }^{52}$ wurden AT2-Zellen als SPC- und EpCampositiv, sowie Fibroblasten als Sca-1-positiv und EpCam-negativ definiert (Abbildung $5 \mathrm{~b}$ und c). ${ }^{52,66}$

Die Analyse der Subpopulationen ergab ein signifikant erhöhtes Vorkommen Sca-1-positiver Fibroblasten sowie EpCam/SPC-doppel-positiver AT2-Zellen in den Lungen Atm-defizienter Mäuse (EpCAM+/SPC+: 29,94 $\pm 3,98 \%, p<0,01$; Sca-1+: 28,95 $\pm 3,87 \%, p<0,01)$ im Vergleich zu Wildtyp-Mäusen $\left(\mathrm{EpCAM}^{+} / \mathrm{SPC}^{+}: 11,23 \pm 3,51 \%\right.$; Sca-1+: $11,09 \pm 1,59 \%$, Abbildung $5 \mathrm{~d}$ und e). 

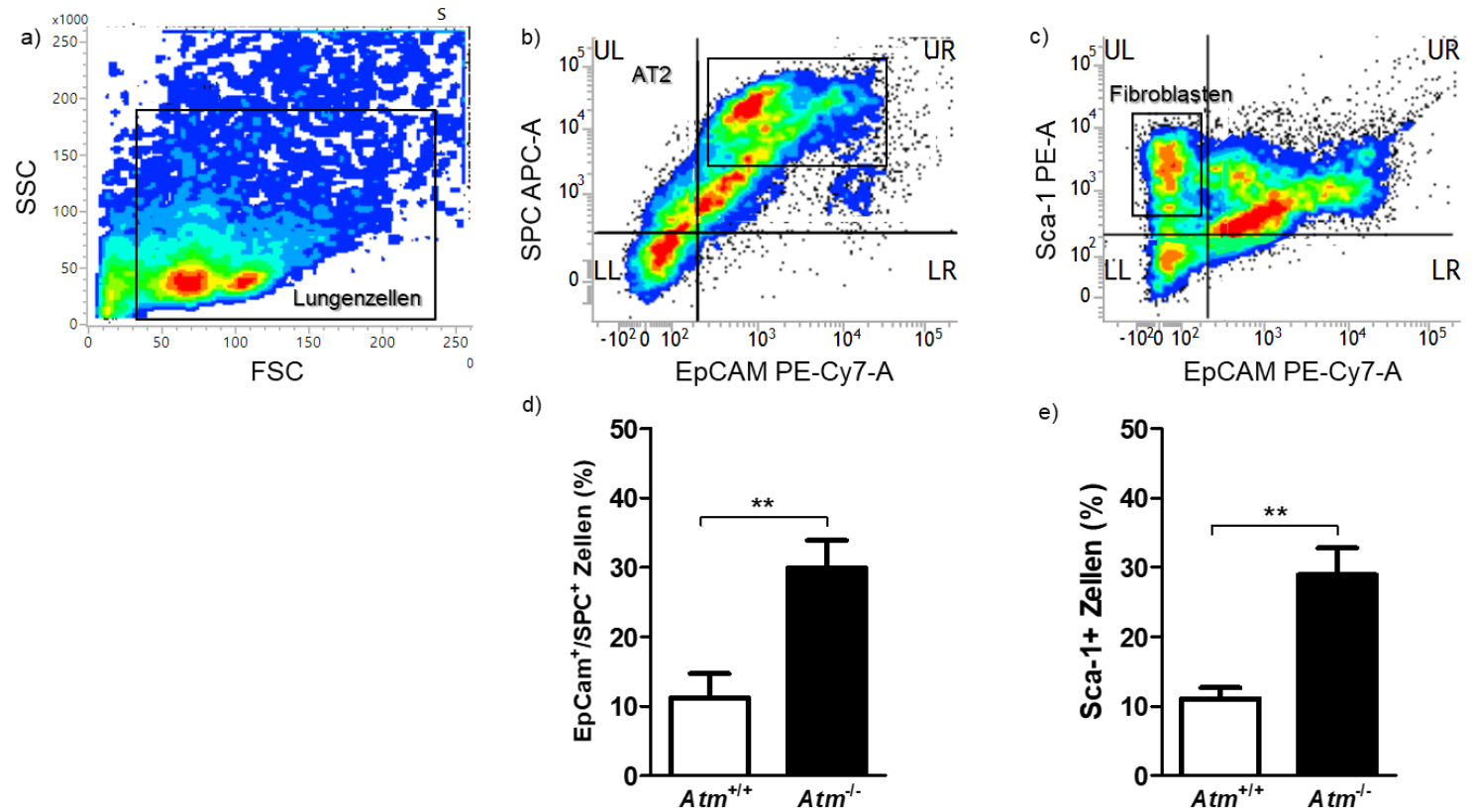

Abbildung 5 Analyse primärer Lungenzellen Atm-defizienter und Wildtyp-Mäuse. Nach Isolation wurden die Zellen oberflächengefärbt, anhand der oben beschriebenen Strategie sortiert und als Dichtediagramm dargestellt. a) Zeigt die Gesamtlungenzellen, b) die SPC- und EpCAMpositiven AT2-Zellen, c) die Sca-1-positiven Fibroblasten. d) Zeigt die Anzahl an Atm-defizienten und Atm-kompetenten AT2-Zellen, e) repräsentiert die Anzahl Atm-defizienter und WildtypFibroblasten-Zellen. Daten sind als Mittelwert \pm SEM angegeben, ${ }^{* *} p<0,01$, pro Gruppe ist $\mathrm{n} \geq 6$.

\subsection{Analyse intrazellulärer ROS}

Oxidativer Stress gilt als einer der pathophysiologischen ursächlichen Mechanismen zur Entstehung der Lungenerkrankung bei A-T. Zur Bestätigung dieses Mechanismus wurden die Lungenzellen aus Atm-defizienten und WildtypMäusen isoliert und mittels Durchflusszytometrie anschließend bezüglich der intrazellulären DCF-Levels anhand der mittleren Fluoreszenzintensität (MFI) aller Lungenzellen sowie der Subpopulationen analysiert. Hierbei zeigte sich ein signifikanter Unterschied des DCF-Levels zwischen Atm-defizienten- und Wildtyp-Gesamtlungenzellen ( Atm $^{-/}: 3968 \pm 609 \mathrm{MFI}$; Atm $^{+/+}: 1185 \pm$ 195,2 MFI, $p<0,01$, Abbildung 6a) sowie den AT2-Zellen (Atm ${ }^{--:} 2967 \pm 134,1 \mathrm{MFI}$; Atm $^{+/+}$: $2215 \pm 264,3 \mathrm{MFI}, p<0,05$, Abbildung 6b). Zwischen den unbehandelten Fibroblasten-Zellen bestand kein signifikanter Unterschied (Abbildung 6c). 

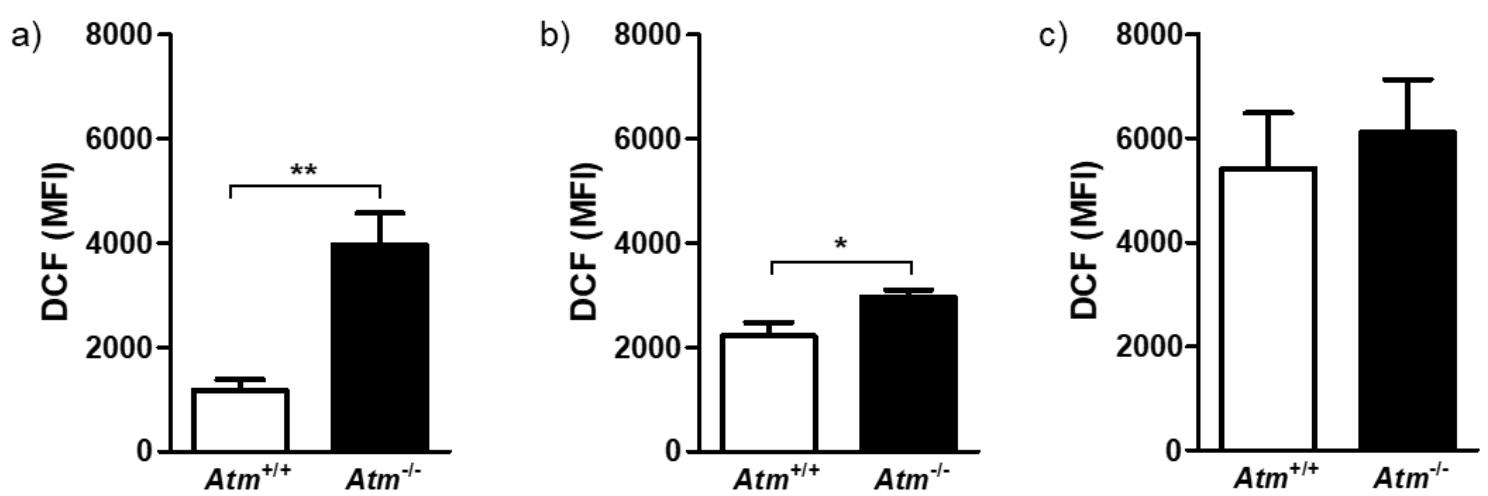

Abbildung 6 Analyse reaktiver Sauerstoffspezies primärer muriner Lungenzellen Atmdefizienter und Wildtyp-Mäusen mittels Durchflusszytometrie. Nach Isolation wurden die einzelnen Lungenzellsubpopulationen anhand ihrer Oberflächenmarker charakterisiert und eingeteilt. a) Repräsentiert die gesamte Lungenzellpopulation, b) zeigt die AT2-Zellen und c) die Fibroblasten. Die Daten sind als Mittelwert \pm SEM angegeben, ${ }^{*} p<0,05,{ }^{*} p<0,01$, pro Gruppe ist $\mathrm{n} \geq 4$. DCF $=2^{\prime}, 7^{\prime}$-dichloroflurescein Diazetat, $\mathrm{MFI}=$ mittlere Fluoreszenzintensität.

\subsection{Einfluss von Bleomycin auf intrazelluläre ROS und oxidativen} Stress von Lungenzellen in vitro

Zur Induktion von oxidativem Stress wurden die isolierten Lungenzellen der Atmdefizienten und Wildtyp-Mäuse für 24 Stunden mit $10 \mathrm{mU}$ Bleomycin stimuliert. Anschließend erfolgte die Analyse mittels Fluoreszenzplattenlesers. Hier zeigte sich ein signifikanter Anstieg des intrazellulären DCF-Levels gemessen in Form von fluoreszierendem 2',7'-Dichlorofluorescein (DCF) (willkürliche Einheit, engl. arbitrary unit, $\mathrm{AU}$ ) in den Atm-defizienten Lungenzellen nach Inkubation mit BLM (Atm ${ }^{-}:$: $60720 \pm 1194$ DCF-Fluoreszenz AU; Atm $^{--}+10$ mU BLM: $65460 \pm 63,22$ DCF-Fluoreszenz AU, $p<0,01$, Abbildung 7), während sich kein signifikanter Unterschied in den Wildtyp-Lungenzellen zeigte. 


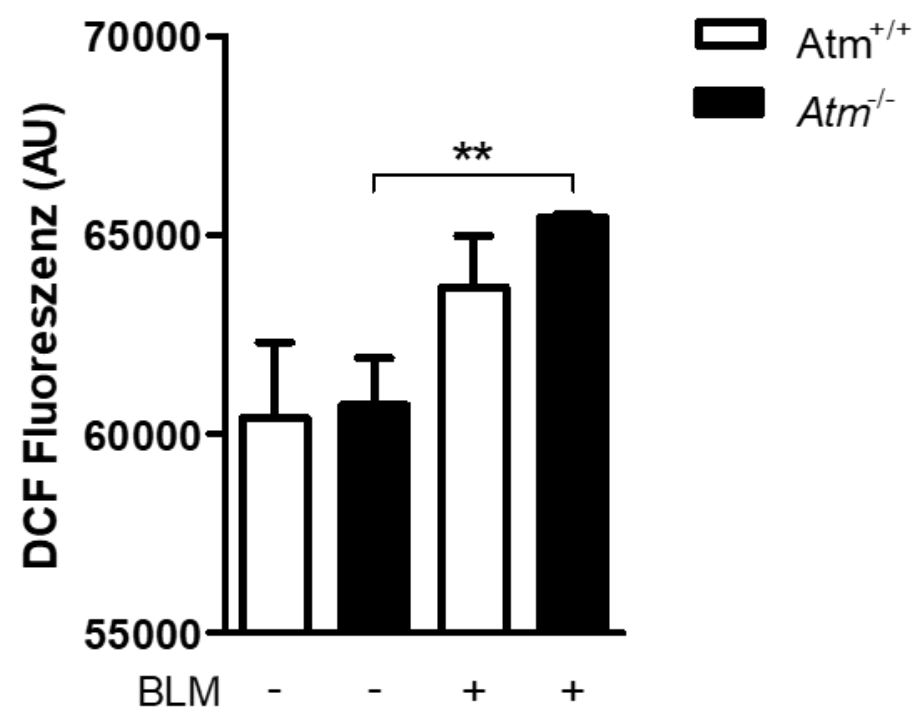

Abbildung 7 Der Effekt von BLM-induziertem oxidativem Stress auf die murinen Lungenzellen. Das DCF-Level der isolierten Atm-defizienten und Wildtyp-Lungenzellen wurde mittels eines Fluoreszenzplattenlesers analysiert. Hierbei zeigte sich ein signifikanter Anstieg der Fluoreszenzen AU in den stimulierten Atm-defizienten Zellen im Verlgeich zu den unbehandelten Atm-defizienten Lungenzellen. Daten sind als Mittelwert \pm SEM angegeben. ${ }^{* *} p<0,01$, pro Gruppe ist $n=4$. DCF $=2^{\prime}, 7^{\prime}$-dichloroflurescein Diazetat, $B L M=$ Bleomycin, $A U=$ arbitrary units.

\subsection{Einfluss von oxidativem Stress auf die Populationen muriner}

\section{Lungenzellen in vitro}

Wie bereits beschrieben sind AT2-Zellen und Fibroblasten tragend für Regeneration und Reparatur des Lungengewebes. Zudem spielen sie im Zuge der Fibrosierung eine wichtige Rolle. Als weiterführende Analyse wurden diese beiden Subpopulationen im Hinblick auf ihre Reaktion nach Stimulation mit BLM untersucht. Es zeigte sich ein tendenzieller prozentualer Anstieg der AT2-Zellen besonders bei den Knockout-Mauszellen. Im Vergleich zu den Wildtyp-Zellen konnte ein signifikanter Unterschied im prozentualen Anteil der AT2-Zellen nach der Stimulation festgestellt werden $\left(\mathrm{Atm}^{-/} \mathrm{EpCAM}^{+} / \mathrm{SPC}^{+}+10 \mathrm{mU}\right.$ BLM: 45,89 \pm $17,75 \%, \mathrm{Atm}^{+/} \mathrm{EpCAM}^{+} / \mathrm{SPC}^{+}+10 \mathrm{mU}$ BLM: 20,29 $\pm 9,09 \%, p<0,05$, Abbildung 8c). 


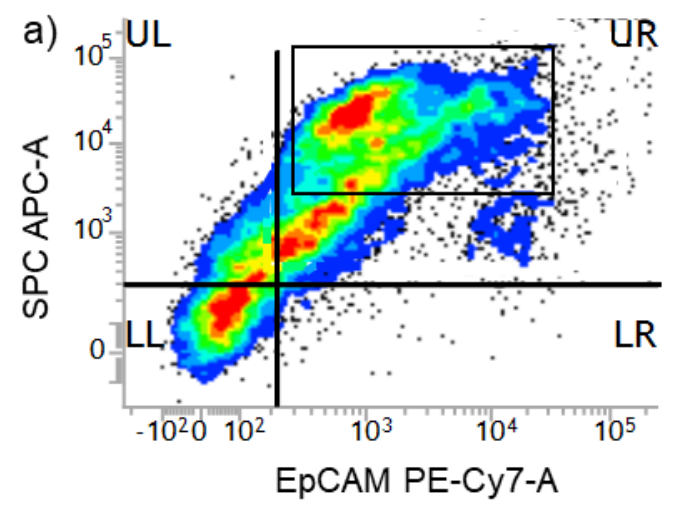

c)

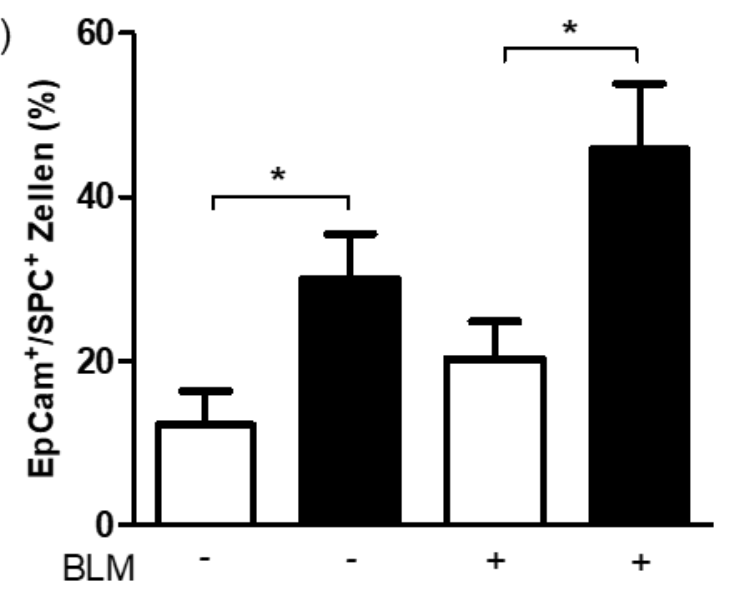

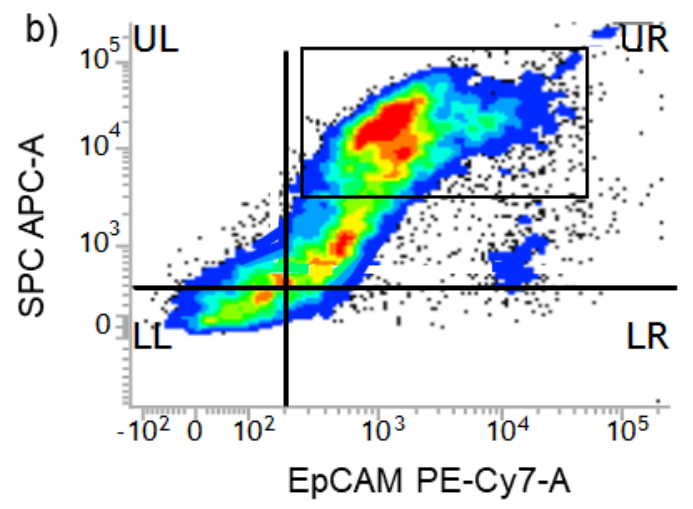

Atm $_{\text {Atm }^{+/}}^{+/}$

Abbildung 8 Der Effekt von BLM auf Atm-defiziente AT2-Zellen. Nach 24-stündiger BLMStimulation wurden die $\mathrm{EpCAM}^{+} / \mathrm{SPC}^{+}$-Zellen mittels Durchflusszytometrie analysiert. a) Zeigt erneut die beispielhafte Dichtedarstellung unstimulierter AT2-Zellen. b) Zeigt die mit $10 \mathrm{mU}$ stimulierten AT2-Zellen. c) Zeigt den prozentualen Anstieg der AT2-Zellen. Dieser war zwar nicht signifikant, jedoch war der prozentuale Anstieg im Vergleich zu den Wildtyp-Zellen weiterhin signifikant erhöht. Daten sind als Mittelwert \pm SEM angegeben, ${ }^{*} p<0,05$, pro Gruppe ist $n \geq 4$. $\mathrm{BLM}=$ Bleomycin.

Bei den Fibroblasten zeigte sich bei beiden Genotypen ein prozentualer Abfall der Sca-1-positiven Zellen. Der Vergleich ergab einen signifikanten Unterschied im Vorkommen zwischen Knockout- und Wildtyp-Zellen $\left(\mathrm{Atm}^{-1-} \mathrm{Sca}-1^{+}+10 \mathrm{mU}\right.$ BLM: 13,20 $\pm 3,98 \%$, Atm $^{+/+}$Sca- $1^{+}+10 \mathrm{mU}$ BLM: 4,93 $\pm 1,93 \%, p<0,01$, Abbildung 9c). 

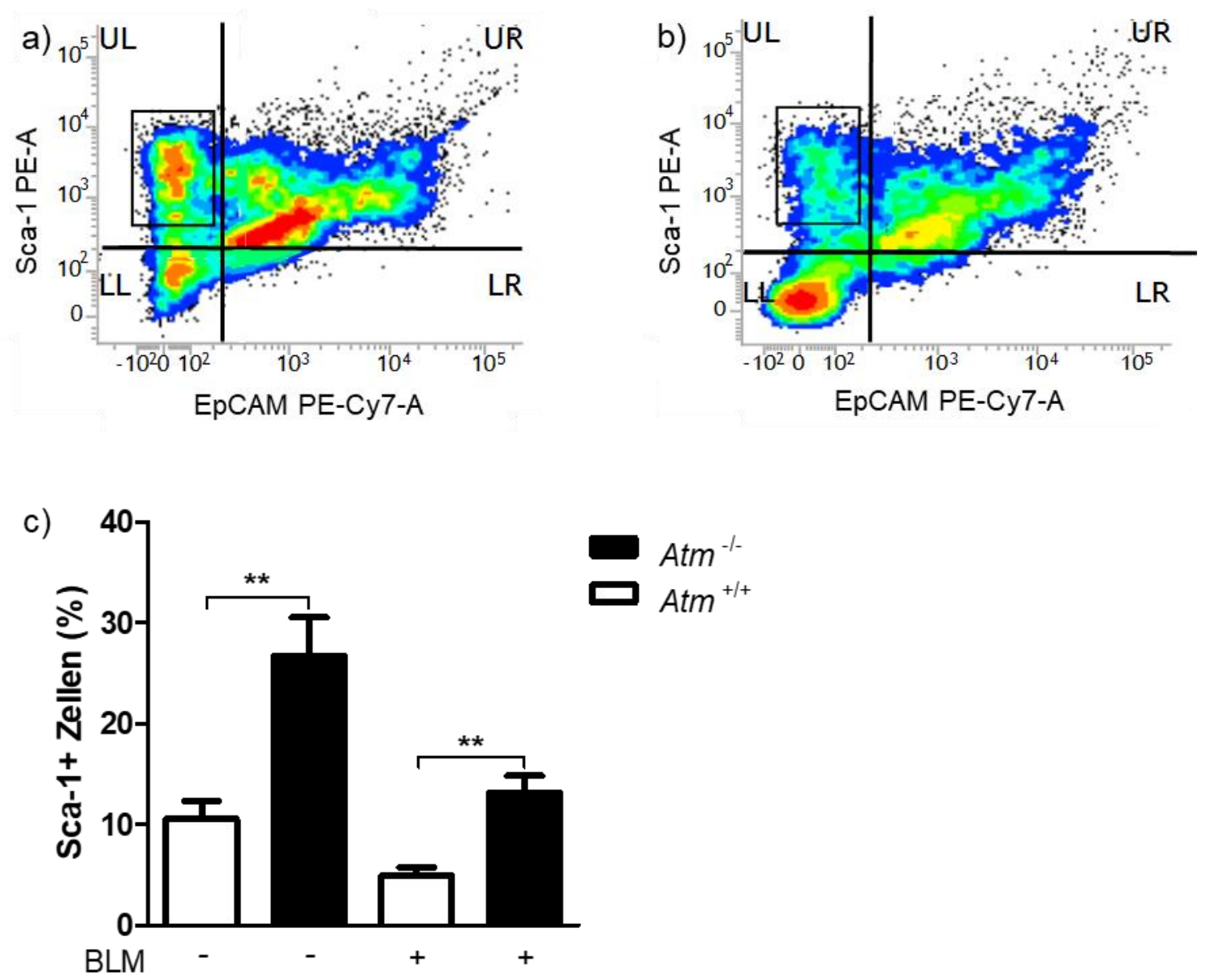

Abbildung 9 Der Effekt von BLM auf Atm-defiziente Fibroblasten. Nach 24-stündiger BLMStimulation wurden die Sca-1+-Zellen mittels Durchflusszytometrie analysiert. a) Zeigt erneut die beispielhafte Dichtedarstellung unstimulierter Fibroblasten, b) zeigt die stimulierten Fibroblasten und c) zeigt den prozentualen nicht-signifikanten Abfall der Fibroblasten. Jedoch war das prozentuale Vorkommen der Atm-defizienten Fibroblasten im Vergleich zu den Wildtyp-Zellen weiterhin signifikant erhöht. Daten sind als Mittelwert \pm SEM angegeben, ${ }^{* *} p<0,01$ pro Gruppe ist $\mathrm{n}=6$. BLM = Bleomycin.

\subsection{Einfluss von Bleomycin auf die Viabilität Atm-defizienter Lungenzellen}

Mit Hilfe des XTT-Assays wurde die Wirkung von BLM auf das Überleben muriner Lungenzellen untersucht. Hierfür wurden die Zellen auf einer 96-Well-Platte ausgesät und mit BLM in verschiedenen Konzentrationen für 24 Stunden inkubiert. 
Vor der eigentlichen Messung wurden die Konzentrationen zunächst in kleinen Schritten austitriert, sodass eine sinnvolle Konzentrationsreihe entstand (Daten nicht gezeigt). Anschließend wurde die optische Dichte im Photometer bei $420 \mathrm{~nm}$ gemessen.

Mit zunehmender Konzentration von BLM sank dabei die Viabilität der Zellen. Ab einer Konzentration von $10 \mathrm{mU}$ BLM konnte ein signifikanter Unterschied in der Viabilität muriner Lungenzellen zwischen den beiden Genotypen festgestellt werden. Mit steigender Konzentration war das Überleben der Atm-kompetenten Zellen deutlich größer als der Atm-defizienten Zellen bei gleicher BLMKonzentration $\left(\mathrm{Atm}^{+/+}+10 \mathrm{mU}\right.$ BLM: 63,50 \pm 1,94\%, $\mathrm{Atm}^{-1}+10 \mathrm{mU}$ BLM: 38,25 $\pm 5,29 \%, p<0,01$, Atm $^{+/+}+20 \mathrm{mU}$ BLM: 63,75 $\pm 1,75 \%$, Atm $^{-/}+20 \mathrm{mU}$ BLM: $32,50 \pm 1,94 \%, p<0,001$, Abbildung 10).

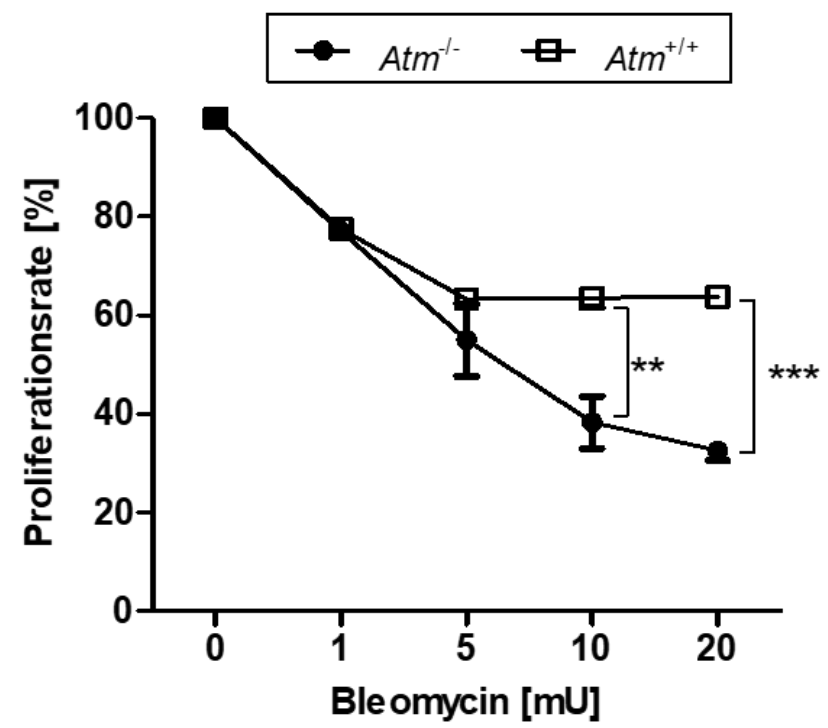

Abbildung 10 Der Effekt von Bleomycin auf die Zellviabilität muriner Lungenzellen in vitro. XTT-Proliferationsanalyse muriner Lungenzellen nach Behandlung mit verschiedenen Konzentrationen Bleomycin ( $1 \mathrm{mU}, 5 \mathrm{mU}, 10 \mathrm{mU}$ und $20 \mathrm{mU}$; pro Gruppe ist $\mathrm{n}=4)$. Als Positivkontrolle diente $70 \%$ iges EtOH (Daten nicht gezeigt). Daten sind als Mittelwert \pm SEM angegeben. ${ }^{* *} p<0,01,{ }^{* *} p<0,001$. EtOH $=$ Ethanol. 


\subsection{Einfluss von Bleomycin auf die DNA-Schädigung Atm-defizienter}

\section{Zellen}

Zur Darstellung der DNA-Schädigung wurden die $\gamma \mathrm{H} 2 \mathrm{AX}$-Proteine der Lungenzellen immunfluoreszenztechnisch angefärbt. Repräsentativ sind in Abbildung 11 die Atm-Knockout-Mauszellen gezeigt. Nach 24-stündiger Inkubation mit BLM zeigte sich eine vermehrte Anzahl an BLM-induzierten DNA-Schäden, dargestellt durch eine erhöhte Anzahl an $\gamma \mathrm{H} 2 \mathrm{AX}$-angefärbter Proteine in den Zellkernen. Optisch ergab sich kein Unterschied zwischen Atm-defizienten und Wildtyp-Zellen.

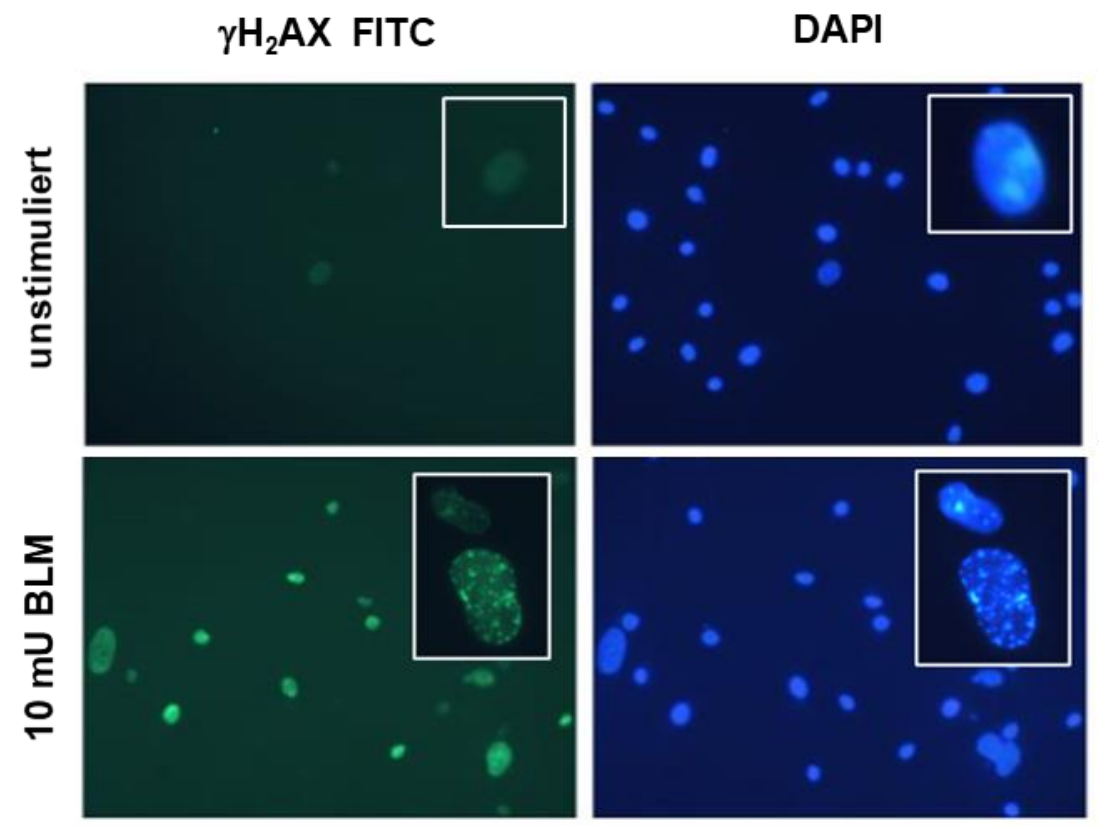

Abbildung 11 Der Effekt von BLM auf murine Lungenzellen Atm-defizienter Mauszellen mittels Immunfluoreszenz dargestellt. Nach Isolation primärer muriner Lungenzellen wurden diese in Chamberslides. ausgesät und mit $10 \mathrm{mU}$ Bleomycin (untere Reihe) 24 Stunden stimuliert und unstimulierten Zellen (obere Reihe) gegenübergestellt. Anschließend wurden die DNASchäden mit anti- $\gamma \mathrm{H} 2 \mathrm{AX}$ (FITC) angefärbt. Die Darstellung erfolgt in 40-facher (großes Bild) bzw. 100-facher (kleiner Bildausschnitt) Vergrößerung.

Zur quantitativen Auswertung erfolgte eine Durchflusszytometer-Analyse des intrazellulären $\gamma \mathrm{H} 2 \mathrm{AX}$-Levels, welches als Marker für intrazellulären DNASchaden gilt. Bei den unstimulierten Lungenzellen zeigte sich kein Unterschied zwischen Atm-defizienten und Wildtyp Lungenzellen. 
Nach Stimulation mit $10 \mathrm{mU}$ BLM zeigten die Wildtyp-Lungenzellen eine schnellere Resolution des DNA-Schadens im Vergleich zu den KnockoutLungenzellen $\left(\mathrm{Atm}^{+++} 3 \mathrm{~h}: 5045 \pm 398,9 \mathrm{MFI}, \mathrm{Atm}^{+/+} 24 \mathrm{~h}: 4108 \pm 294,8 \mathrm{MFI}\right.$, $p<0,05$, Abbildung 12).

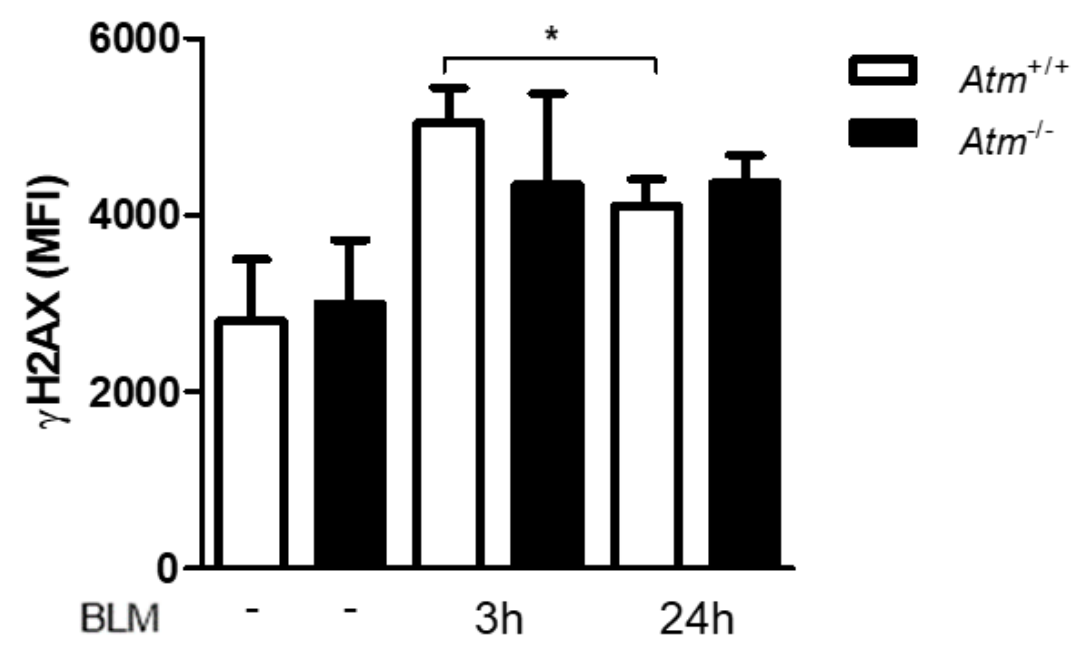

Abbildung 12 Resolution von DNA-Schäden anhand von $\gamma \mathrm{H} 2 \mathrm{AX}$ in Atm-defizienter und Wildtyp-Lungenzellen. Mittels Durchflusszytometer-Analyse wurden primäre murine Lungenzellen nach Isolation für $3 \mathrm{~h}$ bzw. $24 \mathrm{~h}$ mit BLM inkubiert und die DSB anschließend mittels anti- $\gamma \mathrm{H} 2 \mathrm{AX}$ angefärbt. Daten sind als Mittelwert \pm SEM angegeben, ${ }^{*} p<0,05$, pro Gruppe ist $\mathrm{n}=6$. 


\section{Diskussion}

Unter dem mannigfaltigen Symptomkomplex der autosomal-rezessiv vererbten, systemischen Erkrankung A-T beeinflusst insbesondere die chronische Lungenschädigung die Morbidität und Mortalität der betroffenen Patienten nachhaltig. Rezidivierende sinopulmonale Infekte, Immundefizienz und neurodegenerative Prozesse scheinen dabei die Entstehung der Lungenerkrankung zu aggravieren. Die zugrundeliegenden Pathomechanismen sind noch nicht vollständig verstanden, eine gestörte DNA-Reparatur, Inflammation und oxidativer Stress gelten jedoch als zentrale Einflussfaktoren. ${ }^{29}$ Das Ziel der vorliegenden Arbeit war es deshalb, die Rolle von oxidativem Stress auf die Viabilität pulmonaler Zellen genauer zu untersuchen. Die Versuche wurden an Atm-defizienten murinen Lungenzellen durchgeführt. In vivoMausmodelle finden schon seit langer Zeit in Untersuchungen der pulmonalen Pathophysiologie und Pathogenese diverser Lungenerkrankungen Verwendung. ${ }^{98,100}$ Das Atm-Mausmodell repräsentiert dabei viele der Phänotypen von A-T Patienten und stellt somit für diese Arbeit eine gute Methode zur Untersuchung der pathophysiologischen Grundlagen dar. Die Lungenproblematik hingegen findet sich im Mausmodell nur zum Teil wieder, da die Atm-defizienten Mäuse in der Regel zwischen dem zweiten und vierten Lebensmonaten an einem Thymustumor versterben. ${ }^{10,50}$ Folglich scheint nicht genug Lebenszeit zur Entstehung dieser chronischen Manifestationsform zu bleiben. Um die in der Lunge stattfindenden Prozesse vorzeitig simulieren zu können, bedienten wir uns der inflammatorischen Wirkung von Bleomycin. ${ }^{101}$

Die ausgereifte Lunge ist ein komplexes Organ, bestehend aus diversen spezialisierten Zellen, zwei parallelen vaskulären Systemen und einem einzigartigen Immunsystem. ${ }^{61}$ Wie bereits erwähnt sind Reparatur und Zellregeneration Aufgaben von pulmonalen Stamm- und Vorläuferzellen. ${ }^{66}$ Die allgemeine Annahme besteht darin, dass diese Progenitorzellen zu einer bestimmten Untergruppe reifer AT2-Zellen gehören.55,61,67,68 Andere Studien postulieren zudem eine alternative epitheliale Stammzelle in den distalen Lungenabschnitten, die ebenfalls in die Heilung geschädigter Alveolen involviert 
zu sein scheint. Des Weiteren besitzt die murine Lunge mit der BADJ eine einzigartige Transitzone am Übergang der Bronchiolen in die Alveolen. Hier findet sich mit den BASCs eine bestimmte Zellpopulation, welche sowohl Oberflächenmarker der AT2- als auch der sekretorischen Zellen exprimieren. Auch die abschließende Rolle der BASCs ist noch nicht endgültig geklärt und jene Zellart konnte in menschlichen Lungen bisher auch noch nicht identifiziert werden. 54,62,102 Aufgrund der herausragenden Rolle der AT2-Zellen für die Homöostase der Lunge wurde in der vorliegenden Arbeit ein Schwerpunkt auf diese Zellen sowie weiterführend auf die Population der Fibroblasten gelegt. Diese beiden Zelltypen sind in pulmonale Reparaturprozesse involviert und scheinen gleichzeitig die bei A-T beschriebenen Fibrosierungsprozesse voranzutreiben. ${ }^{103}$

Bereits seit vielen Jahren sind verschiedene Methoden zur Isolation muriner Lungenzellen beziehungsweise AT2-Zellen bekannt. Anfangs galten diese jedoch als schwierig durchzuführen und resultierten in divergenten Zellausbeute, reduzierter Zellviabilität und Reinheitsgraden. ${ }^{98,104}$ Daher wurden zunächst zwei verschiedene Isolationsmethoden zur Gewinnung muriner Lungenzellen getestet. Eine bereits in Teilen etablierte Methode bestand darin, die murine Lunge nach Freipräparation mit Hilfe von Dispase und Agarose noch in situ zu fixieren, um sie nach einer gewissen Inkubationszeit entnehmen zu können. ${ }^{98}$ Die Zellgewinnung erfolgte anschließend entweder mechanisch ${ }^{105}$ mit Hilfe eines Skalpells oder des GentleMACS тм, einem halbautomatischen Instrument zur Dissoziation von Geweben in Suspensionen und Homogenaten. ${ }^{104}$ Eine andere, vorher noch nicht etablierte, Methode ermöglichte das direkte Herauspräparieren der Lunge aus dem Situs ohne vorherige Fixierung. Die anschließende Zellgewinnung erfolgte mit Hilfe von Kollagenase und auch bei dieser Methode kann die Zerkleinerung der Lunge mit Hilfe eines Skalpells oder maschinell erfolgen. Beide Methoden besitzen dabei Vor- und Nachteile. Die zweite Methode brachte vor allem eine Zeitersparnis, da keine Inkubationszeiten in situ erforderlich waren, sondern die Lunge direkt heraus präpariert werden konnte. Erstere erforderte zwar mehr Zeit, letztendlich entschieden wir uns jedoch für diese Methode, da eine größere Zellzahl mobilisiert werden konnte. 
Auch bei der anschließenden Zellgewinnung gibt es wie oben bereits erwähnt zwei Möglichkeiten: zum einen die mechanische Zerkleinerung der Lunge beispielsweise mit Hilfe eines Skalpells, zum anderen die maschinelle Methode mittels GentleMACs ${ }^{\mathrm{TM}}$. Die Zerkleinerung der Lunge mit Hilfe eines Skalpells war dabei zwar gewebeschonender, allerdings auch zeitaufwendiger und lieferte insgesamt eine geringere und variable Zellzahl. ${ }^{104-106}$ Initial zeigte sich bei der maschinellen Methode jedoch auch eine zu hohe Anzahl bereits toter Zellen. Nach Optimierung der Zeitspanne der Zerkleinerung konnte schließlich eine optimale Ausbeute erzielt werden. ${ }^{104}$

Nach Isolation der primären Lungenzellen erfolgte eine durchflusszytometrische Charakterisierung der einzelnen Populationen. Die Durchflusszytometrie ist eine oft verwendete Methode zur Identifizierung Zellen anhand ihrer Oberflächenmarker. Sie ist relativ einfach handzuhaben und es können mehrere Parameter gleichzeitig gemessen werden. Da die Charakterisierung und Verteilung der einzelnen Lungenzellpopulationen eine der Ziele dieser Arbeit waren, stellte die Durchflusszytometrie also eine geeignete Methode dar. Weiterhin konnte die Reaktion der einzelnen Populationen auf bestimmte Stimuli untersucht werden. ${ }^{107}$ Um die gewünschten Zellen herauszufiltern und tote oder unerwünschte Populationen zu exkludieren, bedient man sich dem Gating. Mit Hilfe einer negativen, ungefärbten Kontrollgruppe erfolgte zunächst die Einstellung der Gates in der FSC versus SSC Diagrammdarstellung, um so eine korrekte Einstellung des Durchflusszytometrie-Geräts zu garantieren. ${ }^{107}$ Die Experimente zeigten einen erhöhten prozentualen Anteil an AT2-Zellen, definiert als EpCAM- und SPC-doppelt-positiv, als auch der Sca-1-positiven Fibroblasten in den Atm-defizienten Mauslungen im Vergleich zu den Wildtyp-Mauslungen. Das vermehrte Vorkommen dieser Populationen könnte daraufhin deuten, dass diese Zellen in Atm-defizienten Mauslungen verstärkt proliferieren beziehungsweise in die Lunge rekrutiert werden. Dies könnte auf ein grundlegendes, bereits in vivo erhöhtes Stresslevel in der Atm-defizienten Lunge hinweisen, oder weiterhin auf eine reduzierte Kompensation des durch die Zellisolation ausgelösten Stresses im Vergleich zu Atm-kompetenten Lungenzellen. Der prozentual erhöhte Anteil dieser beiden Subpopulationen 
könnte zudem Ausdruck permanenter Reparatur- und Regenerationsprozesse in der Atm-defizienten Lunge sein. Bei ausgeschöpfter Reparaturkapazität bliebe schlussendlich nur noch die zunehmende Fibrosierung, welche auch zur Lungenproblematik in A-T beiträgt. ${ }^{37,99}$

Eine entscheidende Rolle bei der Entstehung der Lungenerkrankung bei A-T scheint eine erhöhte Sensitivität für oxidativen Stress und ROS zu sein. ${ }^{29}$ Die Lunge ist durch ihre gasaustauschende Funktion direkt mit der Außenluft verbunden, weshalb sie besonders anfällig für exogene Stoffe und Verschmutzungen ist. Diese exogenen Trigger enthalten eine hohe Zahl an freien Radikalen, zum Beispiel ROS oder Stickstoffmonoxid, welche zelluläre Proteine, Lipide oder DNA-Sequenzen direkt attackieren. Dies führt zur Aktivierung von Proteasen und Freisetzung diverser inflammatorischer Mediatoren, wie dem Tumor-Nekrosefaktor a (TNFa). Auf zellulärer Ebene spielen in dieser Phase vor allem neutrophile Leukozyten und Makrophagen eine Rolle, die einerseits als wichtige Abwehrzellen gegen bakterielle und virale Infektionen dienen und andererseits selbst durch die Freisetzung von proinflammatorischen Stoffen und Enzymen eine inflammatorische Wirkung erzielen. ${ }^{95}$ Hier schließt sich der Kreis zu den AT2-Zellen, da sie bekanntermaßen mit jenen mobilen Zellen interagieren und darüber hinaus in der Lage sind, beispielsweise durch Sekretion von Lysozymen an der Wirtsabwehr teilzunehmen. ${ }^{59}$ Aufgrund der engen Beziehung zwischen Lunge und Sauerstoff hat diese zur Reduktion des Erkrankungsrisikos biologische Mechanismen entwickelt, um den pathologischen Noxen entgegen zu wirken. ${ }^{95}$

Bei A-T sind die basalen Antwortmechanismen auf oxidativen Stress, wie NF $x B$ und p53, nachweislich erhöht. Zudem weisen ATM-defiziente Zellen einen vermehrten Anteil an oxidierten DNA-Basen auf, was sich durch die wichtige Rolle von ATM als Regulator der zellulären Redoxhomöostase und des antioxidativen Systems erklären lässt. ${ }^{74,96,108}$ Die Hauptquelle intrazellulärer ROS sind die Mitochondrien, kleine Organellen, die als Schnittstelle verschiedener Prozesse, wie der Energiegewinnung oder dem programmierten Zelltod, fungieren. Wie bereits beschrieben sind intrazelluläre enzymatische und 
nicht-enzymatische antioxidative Abwehrmechanismen für den Erhalt der Redoxhomöostase verantwortlich und verhindern eine ROS-Akkumulation. ${ }^{109,110}$ Die Mitochondrien bei A-T scheinen insgesamt beeinträchtigt zu sein und in ihrer Struktur gestört. Zudem ist das mitochondriale Membranpotential herabgesetzt. Infolgedessen zeigen ATM-defiziente Zellen eine mitochondriale ROS-Überproduktion mit verringertem Adenosintriphosphat-Spiegel als Zeichen des Funktionsverlustes. ${ }^{111,112}$ Insbesondere im Zytosol wird ATM mittels Bildung von ATM-Dimeren über Disulfidbrücken durch ROS aktiviert. Nach dieser Aktivierung reguliert ATM diverse Prozesse, um die Wiederherstellung der Redoxhomöostase zu fördern. ${ }^{91,113}$ Hierzu zählen unter anderem die Regulierung der Mitochondrienmasse sowie deren Funktion und Umsatz. ${ }^{111,112}$

Auch bei anderen Erkrankungen ist oxidativer Stress pathophysiologisch relevant. So leiden Patienten mit CF, der weltweit häufigsten autosomal-rezessiv vererbten Erkrankung, ebenfalls unter chronischer pulmonaler Inflammation mit einer Überproduktion an ROS. ${ }^{114}$ Weiterhin beeinflussen auch hier rezidivierende Lungeninfektionen die Lebensqualität und -spanne deutlich. Die Dysbalance in der Produktion und Neutralisation freier Radikale resultiert bei CF aus dem kombinierten Effekt permanenter erhöhter Immunaktivierung und Malabsorption exogen zugeführter Antioxidantien. ${ }^{115}$ Bei A-T konnte bereits eine Beteiligung von oxidativem Stress im Zuge der Neurodegeneration und der vorzeitigen Alterung nachgewiesen werden. ${ }^{116}$ Zusätzlich geht eine erhöhte Konzentration der inflammatorischen Zytokine IL-6 und IL-8 mit einer reduzierten Lungenfunktion und gesteigerten Mortalität einher. ${ }^{34-36}$ Nachweislich haben Patienten mit A-T erhöhte Konzentrationen an ROS mit gleichzeitig reduzierter antioxidativer Kapazität. ${ }^{96,97}$ In einer Pilotstudie von Yeo et al. ${ }^{117}$ konnte bereits eine erhöhte Sensitivität nasaler epithelialer ATM-defizienter Zellen für oxidativen Stress und ROS nachgewiesen werden. Im Mausmodell ließ sich durch Gabe von Antioxidantien der gemessene oxidative Stress reduzieren ${ }^{48,118}$ und sowohl das Membranpotential als auch die mitochondriale Aktivität konnten verbessert werden. ${ }^{48,110,112}$ Dieser Effekt der Antioxidantien wurde auch bei CF registriert. ${ }^{114}$ ROS spielen außerdem als Triggerfaktoren viraler und bakterieller Infektionen eine große Rolle. So induziert beispielsweise das sogenannte RS-Virus (engl. 
respiratory syncytial virus, RSV) schwere Atemwegsinfektionen in jedem Alter, besonders bei Säuglingen führt es jedoch zu komplizierten Verläufen. Der dabei hervorgerufene Endothelschaden wird unter anderem durch eine erhöhte Produktion von ROS geschaffen, indem RSV die NADPH-Oxidase aktiviert. ${ }^{119} \mathrm{Da}$ rezidivierende Infekte als eine der Ursachen der Lungenerkrankung bei A-T gelten, scheint hier eine erneute Verknüpfung zur erhöhten oxidativen Sensibilität ATM-defizienter Zellen zu bestehen.

Nach Isolation und Charakterisierung konnte in den Atm-defizienten Lungenzellen ein erhöhtes Level an ROS nachgewiesen werden. Dieses galt speziell für die AT2-Zellen und deckt sich mit früheren Ergebnissen der Arbeitsgruppe. So konnten Pietzner et al. ${ }^{49}$ im Jahre 2016 eine erhöhte Konzentration an 8-Hydroxy-2'-Desoxyguanosin (8-OH-dG) in den Lungen Atmdefizienter Mäuse messen, was auf erhöhten oxidativen Stress sowie oxidativen DNA-Schaden hindeutet. Wiedererwartend zeigte sich in der Fibroblastenpopulation kein signifikanter Unterschied zwischen Wildtyp- und Atm-defizienten Mäusen, wobei sich über die Gründe nur spekulieren lässt. Eine Möglichkeit besteht darin, dass die hohe Autofluoreszenz und das bereits basal gesteigerte oxidative Stresslevel der Fibroblasten das DCF-Signal im Messkanal überstrahlen. Zudem verändern sich Zellgröße und -granulation der Fibroblasten nach Zugabe des DCFs, wodurch sich diese dem vorab definierten Messbereich entziehen. Folglich könnte die Durchflusszytometrie nicht die geeignetste Methode zur Bestimmung des oxidativen Stresses in Fibroblasten sein.

Zur zusätzlichen Induktion von oxidativem Stress wurde sich die ROSgenerierende Wirkung von BLM zu Nutze gemacht. ${ }^{120}$ Die murine BLM-induzierte Lungenschädigung ist ein häufig verwendetes Modell, um den durch ROSinduzierten Lungenschaden nachzustellen. ${ }^{121}$ Wie oben erwähnt besitzt die murine Lunge eine gewisse Regenerationskapazität. Sie ist in der Lage, den nach einmaliger Gabe von BLM hervorgerufenen Schaden innerhalb von sechs Wochen nahezu vollständig zu reparieren. ${ }^{122}$ Die Lungenschädigung durch BLM verläuft dabei in zwei Phasen. Zunächst steht die inflammatorische Komponente im Vordergrund, während in der zweiten Phase fibrotische Veränderungen 
folgen. BLM scheint in der Lunge diverse Zellen und Prozesse zu beeinflussen, initial konzentriert sich die Schädigung jedoch auf das Lungeninterstitium. ${ }^{122}$ Durch den nach Exposition entstehenden alveolären Epithelschaden treten intrazelluläre Flüssigkeiten und Proteine in den Alveolarraum über. Es kommt zu einem interstitiellen Ödem mit Einstrom inflammatorischer und immunologischer Zellen, sowie AT1-Zellnekrose mit Metaplasie der AT2-Zellen. ${ }^{101,123}$ Die Konzentration inflammatorischer Mediatoren wie beispielsweise TNFa steigt. ${ }^{124}$ Da diese Stoffe in der Lunge bei oxidativem Stress ebenfalls erhöht sind, stellt BLM ein gutes Agens dar, um den oxidativen Stress in der Lunge zu simulieren.

BLM generiert DSB, erhöht die Entstehung von ROS durch rekrutierte aktivierte Entzündungszellen und induziert die Lipidperoxidation, wodurch zusätzlicher oxidativer Stress entsteht. Es kommt zu einer gesteigerten Mitochondrienpermeabilität und der Initiation des programmierten Zelltodes. ${ }^{123,125}$ Alveolärer Zelltod konnte bereits 48 Stunden nach BLM-Exposition beobachtet werden. ${ }^{126} \mathrm{Im}$ zweiten Schritt proliferieren Fibroblasten und differenzieren sich in Myofibroblasten, wodurch sogenannte Fibroblastenherde entstehen. Die dadurch erhöhte Produktion an EZM fördert in der zweiten Phase die Entstehung einer pulmonalen Fibrose. ${ }^{122}$ Die Lungenepithelzellen scheinen besonders anfällig für die BLM-induzierte Apoptose zu sein, wodurch die pulmonale Inflammation und schlussendliche Lungenfibrosierung zusätzlich begünstigt wird. ${ }^{127}$ Viele dieser Vorgänge konnten ebenfalls bei A-T beobachtet werden. ${ }^{40,128,129}$ Während der Regenerationsphase nach Lungenschädigung kommt es zu einer wechselseitigen Interaktion zwischen AT2-Zellen und Fibroblasten. So kann die Anwesenheit von Fibroblasten die Proliferation von AT2-Zellen beschleunigen. Durch Sekretion verschiedener Faktoren aus AT2-Zellen kann im Gegenzug die Fibroblastenproliferation jedoch auch verringert werden. Frühere Studien lassen vermuten, dass eine Dysregulation in dieser Interaktion eine Schlüsselrolle in der Fibrogenese spielt. ${ }^{59,126}$ Das geschädigte Epithel besitzt anschließend verschiedene Reparaturmechanismen. AT2-Zellen scheinen zu proliferieren, wodurch es zur Neubildung sowohl von AT2- als auch AT1-Zellen kommt. Hierdurch kann das Alveolarepithel bezüglich seiner Funktion intakt gehalten 
werden. Darüber hinaus gibt es Hinweise, dass AT2-Zellen apoptotische Zellen phagozytieren und so ebenfalls zur epithelialen Reparatur beitragen. Durch die Expression diverser Membranrezeptoren können sie mit anderen ortsansässigen oder zirkulierenden Zellen und Proteinen interagieren und fungieren so zusätzlich als eine Art immunologischer Zelle. Insgesamt präsentieren sich AT2-Zellen als integrative Einheit mit den Alveolen. ${ }^{54,59,130}$ In den BADJ wurde durch Kim et al. ${ }^{102}$ beobachtet, dass nach BLM-Schaden die oben bereits erwähnten BASCs proliferieren, wodurch diese Zellen sowohl zur Regeneration der Atemwege als auch der Alveolen beitragen können. Ob diese Zellen als Stammzellen fungieren, ist jedoch noch nicht abschließend geklärt. Nichtsdestoweniger besteht die Möglichkeit, dass so ein alternativer Reparaturweg neben der AT2-Zellfunktion konserviert wird. ${ }^{54,102}$

Um die inflammatorische Komponente der Lungenerkrankung bei A-T zu untersuchen, wurden die murinen Lungenzellen nach der Isolation mit $10 \mathrm{mU}$ BLM behandelt und für 24 Stunden inkubiert. Anschließend wurden die DCF-Fluoreszenzen gemessen und mit den unbehandelten Zellen sowie den Wildtyp-Zellen verglichen. Hierbei zeigte sich ein signifikanter Anstieg des oxidativen Stresses in den Atm-defizienten Lungenzellen. In den Wildtyp-Zellen zeigte sich hingegen nur ein geringer Anstieg. Hieraus lässt sich schließen, dass Atm-kompetente Zellen weniger unter dem induzierten oxidativen Stress leiden beziehungsweise diesen besser kompensieren können. Mit Hilfe der Viabilitätsbestimmung konnten wir darüber hinaus belegen, dass mit steigenden Konzentrationen von BLM das Überleben der Atm-defizienten Lungenzellen gegenüber den Wildtyp-Zellen sinkt. Schon bei einer Konzentration von $10 \mathrm{mU}$ zeigte sich ein signifikanter Unterschied. Diese Experimente unterstreichen die ausgeprägte Sensitivität der Atm-defizienten Lungenzellen gegenüber ROS sowie ROS-induzierender Reagenzien. Des Weiteren unterstützen diese Ergebnisse die Theorie, dass die Fähigkeit Atm-defizienter Zellen, sich gegen ROS-induzierten Zellschaden dauerhaft zu schützen, vermindert ist.

Da AT2-Zellen und Fibroblasten wie oben dargelegt eine herausragende Rolle in der Regeneration und Reparatur von Lungengewebe einnehmen, ${ }^{103}$ wurden die 
Subpopulationen nach der Behandlung mit $10 \mathrm{mU}$ BLM ebenfalls mit Hilfe der Durchflusszytometrie untersucht. Hier ließ sich ein Anstieg des prozentualen Vorkommens an AT2-Zellen in Atm-defizienten Mauslungen verzeichnen. Zwar war dieser Anstieg im Vergleich zu den unbehandelten Zellen nicht signifikant, jedoch bestand auch nach der Behandlung mit BLM weiterhin ein signifikanter Unterschied zu den Wildtyp-Zellen. Dies weist auf eine gesteigerte Proliferation der AT2-Zellen nach BLM-Behandlung und damit oxidativem Stress hin und bestätigt die bedeutende Rolle der AT2-Zellen für die pulmonale Homöostase. In der Subpopulation der Fibroblasten wurde zunächst einmal ein prozentualer Abfall beobachtet. Dies erscheint zunächst nicht plausibel, da die Fibroblasten als Teil der EZM für die Reparaturvorgänge ebenfalls bedeutend sind. ${ }^{60}$ Wie jedoch bereits im ersten Abschnitt beschrieben, verändert sich durch Zugabe des BLM erneut die Größe und Granulation der Fibroblastenpopulation und sie entziehen sich dem Messbereich. Bekanntermaßen differenzieren Fibroblasten nach Aktivierung unter anderem in Myofibroblasten. ${ }^{99}$ Hierdurch könnte die Größen- und Granulationsänderung der Fibroblasten nach Stimulation erklärt werden. Nichtsdestotrotz zeigte sich weiterhin ein signifikanter Unterschied zu den Wildtyp-Fibroblasten.

Dass Atm-defiziente Zellen eine erhöhte oxidative DNA-Schädigung aufweisen, konnte bereits mehrfach nachgewiesen werden. ${ }^{49,118}$ Wie bereits geschildert dient das modifizierte Histon $\gamma \mathrm{H} 2 \mathrm{AX}$ als eine Art "Lokalisationsmarker" für DSB. ${ }^{79,90}$ Darüber hinaus bindet H2AX auch das Mediator of DNA-damage checkpoint protein-1 (engl., MDC1) und agiert als Gerüst für den DNA-Reparaturkomplex an der Stelle des Strangbruches. MDC1 wird anschließend durch den MRN-Komplex gebunden und rekrutiert weitere Proteine an die Bruchstelle, wozu unter anderem ATM gehört. ${ }^{131,132}$ Zudem konnten Guo et al. ${ }^{91}$ herausfinden, dass $\gamma \mathrm{H} 2 \mathrm{AX}$ nach BLM-Behandlung auftritt. In der Arbeit von Pietzner et al. ${ }^{49}$ wurde neben einer erhöhten Konzentration an 8-OH-dG in der bronchoalveolären Lavage auch eine erhöhte Anzahl $\gamma \mathrm{H} 2 \mathrm{AX}$ positiver Splenozyten in Atm-defizienten Mäusen im Vergleich zu Wildtyp-Mäusen beschrieben. Nach Bestrahlung mit unterschiedlich hohen Dosen nahm der oxidative Schaden weiter zu und es zeigte sich eine verspätete 
Reparatur der DNA-Schädigungen. ${ }^{49}$ Auch in Patienten mit A-T konnte diese erhöhte Konzentration an oxidativen DNA-Schäden festgestellt werden. ${ }^{116}$ Die Eigenschaft des $\gamma \mathrm{H} 2 \mathrm{AX}$ als Lokalisationsmarker machten wir uns in dieser Arbeit ebenfalls zunutze. Um die DNA-schädigende Wirkung von BLM zu visualisieren, erfolgte zunächst die Immunfluoreszenzfärbung der DSB. Hier manifestierte sich ein erhöhtes Aufkommen von DSB nach Behandlung mit BLM. Optisch ergab sich zwischen den Atm-defizienten und Wildtyp-Lungenzellen kein Unterschied. Zur quantitativen Auswertung analysierten wir die MFI der $\gamma \mathrm{H} 2 \mathrm{AX}-$ exprimierenden Zellen per Durchflusszytometrie und stellten Atm-defiziente und Atm-kompetente Zellen gegenüber. Allio et al. ${ }^{133}$ konnten bereits beobachten, dass eine Behandlung von BLM in ATM-inhibierten AT2-Zellen im Vergleich zu ATM-kompetenten Zellen zu einer signifikant verminderten Zellviabilität führt, was wir mittels XTT in den Lungenzellen ebenfalls zeigen konnten. Zudem bestand eine verzögerte Reparatur von DSB, gemessen durch die verzögerte Elimination von $\gamma \mathrm{H} 2 \mathrm{AX} .{ }^{133}$ Auch diese Ergebnisse konnten wir in dieser Arbeit bestätigen. Nach Stimulation der isolierten Lungenzellen zeigte sich zunächst ein Anstieg der DSB nach drei Stunden. Nach 24 Stunden war ein signifikanter Abfall der MFI Atm-kompetenter Lungenzellen zu beobachten, was für eine zunehmende Resolution des oxidativen DNA-Schadens spricht. Die MFI Atmdefizienter Lungenzellen hingegen blieb nahezu gleich. Atm-defiziente Zellen scheinen also nicht in der Lage zu sein, oxidativ-induzierte DSB zeitnah zu reparieren, wodurch die Gefahr fehlerhafter Transkription zwangsläufig steigt.

Neben den guten Ergebnissen dieser Arbeit unterliegt sie dennoch verschiedenen Limitationen. Die untersuchte Populationsgröße war mit $n \geq$ vier repräsentativ und mit einem definierten Alter von sechs bis neun Wochen hatten die Mäuse alle ein ähnliches Entwicklungsstadium erreicht, jedoch wurden die Mauszellen im Abstand von mehreren Monaten isoliert. Durch die unterschiedlichen Isolationszeitpunkte bestehen andere äußere Umstände, wie beispielsweise die Umgebungs- und Außentemperatur, welche als systematische Fehler die Experimente beeinflussen. Zur Reduktion dieser Verzerrungen wurden die Mäuse innerhalb der Versuchsgruppen alle in gleichen Käfigen unter gleichen Bedingungen gehalten. Die begrenzte Anzahl der $\mathrm{Atm}^{-/}$Nachkommen, die das 
entsprechende Alter erreicht haben, erschwert vorab die Gruppeneinteilung zusätzlich. Für zukünftige Untersuchungen besteht daher die Möglichkeit die untersuchte Population zu vergrößern, sodass die Standardabweichung reduziert und somit bei bestimmten Experimenten auch signifikante Ergebnisse erzielt werden können. Eine einzelne Gabe von BLM ruft die oben beschrieben Veränderungen in der Lunge hervor, sodass die gewählte 24-stündige Stimulation mit BLM die entzündlichen Veränderungen und somit die erste Phase der Lungenerkrankung bei A-T widerspiegelt. ${ }^{122}$ Die Fibrose als chronischen Prozess und damit auch die Rolle der Fibroblasten bei der Fibroseentstehung lassen sich anhand dieser Methode nicht gänzlich beurteilen. Dies war jedoch auch nicht Ziel der vorliegenden Arbeit. Da die Anzahl Sca-1-positiver Fibroblasten in der Atm-defizienten Lunge bereits nach Isolation signifikant erhöht war, entsteht trotzdem die Vermutung, dass hier bereits basale Fibrosevorgänge in den unstimulierten Atm-defizienten Lungen begonnen haben. Zwar wurde eine Analyse der Populationen bezüglich des oxidativen Stresslevels vorgenommen, eine Differenzierung im Vorkommen der DSB erfolgte jedoch nicht. Diese weiterführende Auswertung könnte die Informationen über die pathophysiologischen Grundlagen der Lungenerkrankung bei A-T ergänzen.

Zusammenfassend konnte in der vorliegenden Arbeit ein grundlegend höheres oxidatives Stresslevel Atm-defizienter Lungenzellen nachgewiesen werden, welches sich durch Behandlung mit BLM zusätzlich erhöhen ließ. Bei steigendem oxidativem Stress versagen die zellulären Kompensationsmechanismen Atm-defizienter Zellen und die Viabilität sinkt signifikant im Vergleich zu Atm-kompetenten Zellen. Ebenso fehlt den Atm-defizienten Zellen im Vergleich zu Wildtyp-Lungenzellen die Fähigkeit zur zeitnahen Resolution von DSB. Zudem fanden sich Hinweise für die tragende Rolle von AT2-Zellen und Fibroblasten in der Pathogenese der Lungenerkrankung bei A-T. Die Ergebnisse dieser Arbeit unterstützen also die Hypothese, dass eine erhöhte Sensitivität der pulmonalen Zellen von A-T Patienten auf ROS vorliegt. Daraus lässt sich schließen, dass oxidativer Stress wesentlich an der Entstehung der Lungenerkrankung bei A-T beteiligt ist. 


\section{Ausblick}

Die vorliegenden Ergebnisse bestätigen die erhöhte Sensitivität der Atmdefizienten Lungenzellen gegenüber ROS. Vor diesem Hintergrund wäre ein möglicher therapeutischer Ansatz von Interesse, der mittels antioxidativer Substanzen das zelluläre Stresslevel der Subpopulationen reduzieren und die Resolution der DSB fördern könnte. Des Weiteren stellt BLM einen exogenen Trigger für oxidativen Stress dar. Da endogener oxidativer Stress vor allem durch physiologische Peroxidation und Zellen, wie neutrophile Granulozyten, entsteht, kann abschließend nicht gesagt werden, ob durch endogenen Stress die gleichen Mechanismen in Gang gesetzt werden, wie durch den exogen induzierten. Ein nächster Ansatzpunkt könnte daher darin bestehen, die endogenen Trigger für oxidativen Stress in Atm-defizienten Zellen näher zu untersuchen. $\mathrm{Da}$ in der vorliegenden Arbeit die einzelnen Subpopulationen nach Isolation bereits ohne weiteren Stimulus untersucht wurden, stellt dies schon teilweise das endogene basale Stresslevel dar.

Darüber hinaus könnte interessant sein, die murinen Lungen über mehrere Wochen mit BLM in vivo zu stimulieren und die Lungenzellen anschließend mit Hilfe der beschriebenen Methode zu isolieren, um deren Reaktion auf den vorab erzeugten oxidativen Stress mit den verwendeten Methoden zu analysieren. Dies entspräche einem physiologischeren Ablauf der Lungenmanifestation bei A-T. Überdies könnten dann neben den entzündlichen auch die fibrotischen Veränderungen der Lungenmanifestation untersucht und die Rolle muriner Fibroblasten für die Entstehung der Lungenfibrose bei A-T ebenfalls genauer begutachtet werden.

Wie von Barlow et al. ${ }^{10}$ bereits beschrieben spiegelt das Atm-Mausmodell viele der phänotypischen Eigenschaften von A-T wider. Um einen noch besseren Vergleich des murinen Mausmodells mit den A-T Patienten zu erreichen, besteht die Möglichkeit, die durchgeführten Versuche zusätzlich an humanen Lungenzellen, wie beispielsweise der humanen Lungenkarzinomzellreihe A-549, welche den menschlichen AT2-Zellen ähneln, durchzuführen. Um die aus Atm- 
defizienten Mäusen isolierten Lungenzellen zu simulieren, wäre der Einsatz eines ATM-Inhibitors vorstellbar. Anschließend bestünde die Möglichkeit, durch Zugabe von Antioxidantien eine potenzielle Reduktion des oxidativen Stresslevels in humanen Zellen zu untersuchen. Gleiches gilt für die murinen Zellen. 


\section{Zusammenfassung}

Unter dem vielseitigen Symptomkomplex der autosomal-rezessiv vererbten Erkrankung Ataxia-teleangiectasia (A-T) nimmt die Lungenschädigung eine herausragende Rolle ein. Sie beeinflusst die Morbidität und Mortalität der Erkrankung durch rezidivierende Infekte, Bronchiektasien sowie akutes oder chronisches Lungenversagen nachhaltig. Als pathophysiologische Grundlage gilt oxidativer Stress mit einer erhöhten Sensitivität für reaktive Sauerstoffspezies (ROS) und DNA-schädigende Reagenzien. Das aus dem gleichnamigen Gen resultierende Protein ATM wird durch das Vorkommen von DNADoppelstrangbrüchen (DSB) und ROS auf verschiedene Arten aktiviert und reguliert anschließend diverse Prozesse wie der DNA-Reparatur und den zellulären Stressantwortmechanismen. Ziel dieser Arbeit war es die Sensitivität von ATM-defizienten Lungenzellen im Hinblick auf oxidativen Stress näher zu untersuchen. Hierfür wurden Atm-defiziente murine Lungenzellen spontan und nach Stimulation mit Bleomycin (BLM) auf ihre prozentuale Verteilung in der Lunge, auf den Level von ROS, ihre Viabilität und ROS-induzierte DNA-Schäden hin untersucht. Spontan zeigte sich ein signifikant erhöhtes Vorkommen von Alveolarepithelzellen vom Typ 2 (AT2-Zellen) in Atm-defizienten Mauslungen im Vergleich zu Wildtyp-Lungen, welches sich durch die Stimulation mit BLM noch verstärkte und auf erhöhte Regenerations- und Reparaturvorgänge in der Lunge hindeutet. Zudem ist der intrazelluläre Level an ROS in den Lungenzellen und AT2-Zellen signifikant erhöht. Mit steigenden Konzentrationen an BLM sank die Zellviabilität pulmonaler Atm-defizienter Zellen deutlich und die Resolution von DNA-Schäden ist im Vergleich zu Wildtyp-Zellen verzögert. Die Ergebnisse der Arbeit deuten auf eine Beteiligung von oxidativem Stress und DNA-Schäden als pathophysiologische Komponente bei der Entstehung der Lungenmanifestation bei A-T hin. 


\section{Summary}

Among the varied symptoms of Ataxia-teleangiectasia (A-T), an autosomalrecessive inherited disease, the lung manifestation plays an outstanding role. Due to recurrent airway infections, bronchiectasis and acute or chronic lung failure, the lung manifestation has a lasting impact on morbidity and mortality. The pathophysiological backgrounds are thought to be an increased sensitivity to oxidative stress caused by reactive oxygen species (ROS) and DNA-damaging reagents. Resulting from the correspondent gene, the protein ATM is activated in different ways by the occurrence of DNA double-strand-breaks (DSB) and ROS and then regulates various processes such as DNA repair and cellular stress response mechanisms. To investigate the sensitivity of ATM-deficient lung cells to oxidative stress, we examined Atm-deficient murine lung cells spontaneously and after stimulation with Bleomycin (BLM) particularly regarding to their level of ROS, their viability and ROS-induced DNA damage. Spontaneously, there was a significant elevated occurrence of alveolar epithelial cells type 2 (AEC2) in Atmdeficient murine lungs compared to wildtype-lungs. This occurrence was further enhanced by the stimulation with BLM and indicated increased regeneration and repair processes in the lungs. In addition, intracellular oxidative stress was significantly elevated in the lung cells and AEC2 cells. With rising concentrations of BLM, the cell viability of pulmonary Atm-deficient cells decreased considerably, and the resolution of DNA damage was delayed compared to wild-type cells.

Our results indicate the involvement of oxidative stress and DNA damage as a pathophysiological component in the development of lung manifestation in A-T. 


\section{Literaturverzeichnis}

1. Orphanet. Ataxia-Teleangiectasia. https://www.orpha.net/consor/cgibin/OC_Exp.php?Lng=DE\&Expert=100. Updated October 2007. Accessed August 19, 2020.

2. Rothblum-Oviatt C, Wright J, Lefton-Greif MA, McGrath-Morrow SA, Crawford TO, Lederman HM. Ataxia telangiectasia: a review. Orphanet J Rare Dis. 2016;11(1):159. doi:10.1186/s13023-016-0543-7.

3. Henner K. A propos de la description par Mme Louis-Bar de I'"Ataxia teleangiectasia". Priorité de la description, par Lad. Syllaba et K. Henner en 1926, du réseau vasculaire conjonctival. Rev Neurol (Paris). 1968;118(1):6063.

4. Boder E, Sedgwick RP. Ataxia-telangiectasia; a familial syndrome of progressive cerebellar ataxia, oculocutaneous telangiectasia and frequent pulmonary infection. Pediatrics. 1958;21(4):526-554.

5. Gatti RA, Becker-Catania S, Chun $\mathrm{HH}$, et al. The pathogenesis of ataxiatelangiectasia. Learning from a Rosetta Stone. Clin Rev Allergy Immunol. 2001;20(1):87-108. doi:10.1385/CRIAI:20:1:87.

6. Micol R, Ben Slama L, Suarez F, et al. Morbidity and mortality from ataxiatelangiectasia are associated with ATM genotype. J Allergy Clin Immunol. 2011;128(2):382-9.e1. doi:10.1016/j.jaci.2011.03.052.

7. Gilad S, Chessa L, Khosravi R, et al. Genotype-phenotype relationships in ataxia-telangiectasia and variants. Am J Hum Genet. 1998;62(3):551-561. doi:10.1086/301755.

8. Verhagen MMM, Last JI, Hogervorst FBL, et al. Presence of ATM protein and residual kinase activity correlates with the phenotype in ataxia-telangiectasia: a genotype-phenotype study. Hum Mutat. 2012;33(3):561-571. doi:10.1002/humu.22016. 
9. Taylor AMR, Lam Z, Last JI, Byrd PJ. Ataxia telangiectasia: more variation at clinical and cellular levels. Clin Genet. 2015;87(3):199-208. doi:10.1111/cge.12453.

10.Barlow C, Hirotsune S, Paylor R, et al. Atm-deficient mice: a paradigm of ataxia telangiectasia. Cell. 1996;86(1):159-171.

11.Nissenkorn A, Levy-Shraga Y, Banet-Levi Y, Lahad A, Sarouk I, ModanMoses D. Endocrine abnormalities in ataxia telangiectasia: findings from a national cohort. Pediatr Res. 2016;79(6):889-894. doi:10.1038/pr.2016.19.

12.Schubert R, Reichenbach J, Zielen S. Growth factor deficiency in patients with ataxia telangiectasia. Clin Exp Immunol. 2005;140(3):517-519. doi:10.1111/j.1365-2249.2005.02782.x.

13.Voss S, Pietzner J, Hoche F, et al. Growth retardation and growth hormone deficiency in patients with Ataxia telangiectasia. Growth Factors. 2014;32(34):123-129. doi:10.3109/08977194.2014.939805.

14.McKinnon PJ. ATM and ataxia telangiectasia. EMBO Rep. 2004;5(8):772-776. doi:10.1038/sj.embor.7400210.

15.Stray-Pedersen A, Borresen-Dale AL, Paus E, Lindman CR, Burgers T, Abrahamsen TG. Alpha fetoprotein is increasing with age in ataxiatelangiectasia. European Journal of Paediatric Neurology. 2007;11(6):375380. doi:10.1016/j.ejpn.2007.04.001.

16.Waldmann T, Mcintire KR. SERUM-ALPHA-FETOPROTEIN LEVELS IN PATIENTS WITH ATAXIA-TELANGIECTASIA. The Lancet. 1972;300(7787):1112-1115. doi:10.1016/S0140-6736(72)92717-1.

17.Crawford TO. Ataxia Telangiectasia. Seminars in Pediatric Neurology. 1998;(5):287-294. doi:10.1006/rwei.1999.0066.

18.Crawford TO, Mandir AS, Lefton-Greif MA, et al. Quantitative neurologic assessment of ataxia-telangiectasia. Neurology. 2000;54(7):1505-1509. 
19.Schubert Rea. Deficiencies in CD4+ and CD8+ T cell subsets in ataxia telangiectasia. 2002.

20.Suarez F, Mahlaoui N, Canioni D, et al. Incidence, presentation, and prognosis of malignancies in ataxia-telangiectasia: a report from the French national registry of primary immune deficiencies. $J$ Clin Oncol. 2015;33(2):202-208. doi:10.1200/JCO.2014.56.5101.

21.Reiman A, Srinivasan V, Barone G, et al. Lymphoid tumours and breast cancer in ataxia telangiectasia; substantial protective effect of residual ATM kinase activity against childhood tumours. Br J Cancer. 2011;105(4):586-591. doi:10.1038/bjc.2011.266.

22.Crawford TO, Skolasky RL, Fernandez R, Rosquist KJ, Lederman HM. Survival probability in ataxia telangiectasia. Arch Dis Child. 2006;91(7):610611. doi:10.1136/adc.2006.094268.

23.Morrell D, Cromartie E, Swift M. Mortality and cancer incidence in 263 patients with ataxia-telangiectasia. J Natl Cancer Inst. 1986;77(1):89-92.

24.Bott L, Lebreton J, Thumerelle C, Cuvellier J, Deschildre A, Sardet A. Lung disease in ataxia-telangiectasia. Acta Paediatr. 2007;96(7):1021-1024. doi:10.1111/j.1651-2227.2007.00338.x.

25. Cabana MD, Crawford TO, Winkelstein JA, Christensen JR, Lederman HM. Consequences of the Delayed Diagnosis of Ataxia-Telangiectasia. Pediatrics. 1998;102(1):98-100. doi:10.1542/peds.102.1.98.

26.Lavin MF, Gueven N, Bottle S, Gatti RA. Current and potential therapeutic strategies for the treatment of ataxia-telangiectasia. Br Med Bull. 2007;8182:129-147. doi:10.1093/bmb/ldm012.

27.Amirifar P, Ranjouri MR, Yazdani R, Abolhassani H, Aghamohammadi A. Ataxia-telangiectasia: A review of clinical features and molecular pathology. Pediatr Allergy Immunol. 2019. doi:10.1111/pai.13020. 
28.Devaney R, Pasalodos S, Suri M, Bush A, Bhatt JM. Ataxia telangiectasia: presentation and diagnostic delay. Arch Dis Child. 2017;102(4):328-330. doi:10.1136/archdischild-2016-310477.

29.McGrath-Morrow SA, Gower WA, Rothblum-Oviatt C, et al. Evaluation and management of pulmonary disease in ataxia-telangiectasia. Pediatr Pulmonol. 2010;45(9):847-859. doi:10.1002/ppul.21277.

30.Pagano G, Korkina LG, Brunk UT, et al. Congenital disorders sharing oxidative stress and cancer proneness as phenotypic hallmarks: prospects for joint research in pharmacology. Med Hypotheses. 1998;51(3):253-266. doi:10.1016/s0306-9877(98)90084-6.

31.Garbers C, Heink S, Korn T, Rose-John S. Interleukin-6: designing specific therapeutics for a complex cytokine. Nat Rev Drug Discov. 2018;17(6):395412. doi:10.1038/nrd.2018.45.

32. Rincon M, Irvin CG. Role of IL-6 in asthma and other inflammatory pulmonary diseases. Int J Biol Sci. 2012;8(9):1281-1290. doi:10.7150/ijbs.4874.

33.Michael S, Montag M, Dott W. Pro-inflammatory effects and oxidative stress in lung macrophages and epithelial cells induced by ambient particulate matter. Environ Pollut. 2013;183:19-29. doi:10.1016/j.envpol.2013.01.026.

34.McGrath-Morrow SA, Collaco JM, Crawford TO, et al. Elevated serum IL-8 levels in ataxia telangiectasia. $J$ Pediatr. 2010;156(4):682-4.e1. doi:10.1016/j.jpeds.2009.12.007.

35.McGrath-Morrow SA, Collaco JM, Detrick B, Lederman HM. Serum Interleukin-6 Levels and Pulmonary Function in Ataxia-Telangiectasia. $J$ Pediatr. 2016;171:256-61.e1. doi:10.1016/j.jpeds.2016.01.002.

36.McGrath-Morrow SA, Ndeh R, Collaco JM, et al. Inflammation and transcriptional responses of peripheral blood mononuclear cells in classic ataxia telangiectasia. PLoS ONE. 2018;13(12):e0209496. doi:10.1371/journal.pone.0209496. 
37. Bhatt JM, Bush A, van Gerven M, et al. ERS statement on the multidisciplinary respiratory management of ataxia telangiectasia. Eur Respir Rev. 2015;24(138):565-581. doi:10.1183/16000617.0066-2015.

38.Swenson C, Schraufnagel D, Sadikot R. What is Bronchiectasis? Am J Respir Crit Care Med. 2017;195(8):P15-P16. doi:10.1164/rccm.1958P15.

39.Lefton-Greif MA, Crawford TO, Winkelstein JA, et al. Oropharyngeal dysphagia and aspiration in patients with ataxia-telangiectasia. $J$ Pediatr. 2000;136(2):225-231.

40.Schroeder SA, Swift M, Sandoval C, Langston C. Interstitial lung disease in patients with ataxia-telangiectasia. Pediatr Pulmonol. 2005;39(6):537-543. doi:10.1002/ppul.20209.

41.Nowak-Wegrzyn A, Crawford TO, Winkelstein JA, Carson KA, Lederman HM. Immunodeficiency and infections in ataxia-telangiectasia. $J$ Pediatr. 2004;144(4):505-511. doi:10.1016/j.jpeds.2003.12.046.

42. Oxelius VA, Berkel Al, Hanson LA. IgG2 deficiency in ataxia-telangiectasia. $N$ Engl J Med. 1982;306(9):515-517. doi:10.1056/NEJM198203043060905.

43.Schroeder SA, Zielen S. Infections of the respiratory system in patients with ataxia-telangiectasia. Pediatr Pulmonol. 2014;49(4):389-399. doi:10.1002/ppul.22817.

44. Bhatt JM, Bush A. Microbiological surveillance in lung disease in ataxia telangiectasia. Eur Respir J. 2014;43(6):1797-1801. doi:10.1183/09031936.00141413.

45.McGrath-Morrow S, Lefton-Greif M, Rosquist K, et al. Pulmonary function in adolescents with ataxia telangiectasia. Pediatr Pulmonol. 2008;43(1):59-66. doi:10.1002/ppul.20738.

46.McGrath-Morrow SA, Lederman HM, Aherrera AD, et al. Pulmonary function in children and young adults with ataxia telangiectasia. Pediatr Pulmonol. 2014;49(1):84-90. doi:10.1002/ppul.22760. 
47.Barlow C, Dennery PA, Shigenaga MK, et al. Loss of the ataxia-telangiectasia gene product causes oxidative damage in target organs. Proc Natl Acad Sci U S A. 1999;96(17):9915-9919. doi:10.1073/pnas.96.17.9915.

48.Schubert R, Erker L, Barlow C, et al. Cancer chemoprevention by the antioxidant tempol in Atm-deficient mice. Hum Mol Genet. 2004;13(16):17931802. doi:10.1093/hmg/ddh189.

49.Pietzner J, Merscher BM, Baer PC, et al. Low-dose irradiation prior to bone marrow transplantation results in ATM activation and increased lethality in Atm-deficient mice. Bone Marrow Transplant. 2016;51(4):619. doi:10.1038/bmt.2016.22.

50.Eickmeier O, Kim SY, Herrmann E, et al. Altered mucosal immune response after acute lung injury in a murine model of Ataxia Telangiectasia. BMC Pulm Med. 2014;14:93. doi:10.1186/1471-2466-14-93.

51.Junqueira LC, Carneiro J. Histologie: Zytologie, Histologie und mikroskopische Anatomie des Menschen. Unter Berücksichtigung der Histophysiologie. Vierte, korrigierte und aktualisierte Auflage. Berlin, Heidelberg: Springer Berlin Heidelberg; 1996. Springer-Lehrbuch.

52.Leeman KT, Fillmore CM, Kim CF. Lung stem and progenitor cells in tissue homeostasis and disease. Curr Top Dev Biol. 2014;107:207-233. doi:10.1016/B978-0-12-416022-4.00008-1.

53.Zepp JA, Zacharias WJ, Frank DB, et al. Distinct Mesenchymal Lineages and Niches Promote Epithelial Self-Renewal and Myofibrogenesis in the Lung. Cell. 2017;170(6):1134-1148.e10. doi:10.1016/j.cell.2017.07.034.

54.Tata PR, Rajagopal J. Plasticity in the lung: making and breaking cell identity. Development. 2017;144(5):755-766. doi:10.1242/dev.143784.

55.Rock JR, Hogan BLM. Epithelial progenitor cells in lung development, maintenance, repair, and disease. Annu Rev Cell Dev Biol. 2011;27:493-512. doi:10.1146/annurev-cellbio-100109-104040. 
56.Basil MC, Morrisey EE. Lung regeneration: a tale of mice and men. Semin Cell Dev Biol. 2020;100:88-100. doi:10.1016/j.semcdb.2019.11.006.

57.Yang J, Hernandez BJ, Martinez Alanis D, et al. The development and plasticity of alveolar type 1 cells. Development. 2016;143(1):54-65. doi:10.1242/dev.130005.

58.Crapo JD, Barry BE, Gehr P, Bachofen M, Weibel ER. Cell number and cell characteristics of the normal human lung. Am Rev Respir Dis. 1982;126(2):332-337. doi:10.1164/arrd.1982.126.2.332.

59.Fehrenbach H. Alveolar epithelial type II cell: defender of the alveolus revisited. Respir Res. $2001 ; 2(1): 33-46$. doi:10.1186/rr36.

60.White ES. Lung extracellular matrix and fibroblast function. Ann Am Thorac Soc. 2015;12 Suppl 1:S30-3. doi:10.1513/AnnalsATS.201406-240MG.

61.Chen F, Fine A. Stem Cells in Lung Injury and Repair. Am J Pathol. 2016;186(10):2544-2550. doi:10.1016/j.ajpath.2016.05.023.

62.Basil MC, Katzen J, Engler AE, et al. The Cellular and Physiological Basis for Lung Repair and Regeneration: Past, Present, and Future. Cell Stem Cell. 2020;26(4):482-502. doi:10.1016/j.stem.2020.03.009.

63.Brown LM, Malkinson AM, Rannels DE, Rannels SR. Compensatory lung growth after partial pneumonectomy enhances lung tumorigenesis induced by 3-methylcholanthrene. Cancer Res. 1999;59(20):5089-5092.

64.Butler JP, Loring SH, Patz S, Tsuda A, Yablonskiy DA, Mentzer SJ. Evidence for adult lung growth in humans. N Engl J Med. 2012;367(3):244-247. doi:10.1056/NEJMoa1203983.

65.Jain R, Barkauskas CE, Takeda N, et al. Plasticity of Hopx(+) type I alveolar cells to regenerate type II cells in the lung. Nat Commun. 2015;6:6727. doi:10.1038/ncomms7727. 
66.McQualter JL, Brouard N, Williams B, et al. Endogenous fibroblastic progenitor cells in the adult mouse lung are highly enriched in the sca-1 positive cell fraction. Stem Cells. 2009;27(3):623-633. doi:10.1634/stemcells.2008-0866.

67.Barkauskas CE, Cronce MJ, Rackley CR, et al. Type 2 alveolar cells are stem cells in adult lung. $J$ Clin Invest. 2013;123(7):3025-3036. doi:10.1172/JCI68782.

68.Desai TJ, Brownfield DG, Krasnow MA. Alveolar progenitor and stem cells in lung development, renewal and cancer. Nature. 2014;507(7491):190-194. doi:10.1038/nature12930.

69.Savitsky K, Bar-Shira A, Gilad S, et al. A single ataxia telangiectasia gene with a product similar to PI-3 kinase. Science. 1995;268(5218):1749-1753.

70.Savitsky et al. A Single Ataxia Telangiectasia Gene with a Product Similar to P1-3 Kinase.

71.Chen G, Y.-H. P. Lee E. The Product of the ATM Gene Is a 370-kDa Nuclear Phosphoprotein. J Biol Chem. 1996;271(52):33693-33697. doi:10.1074/jbc.271.52.33693.

72.Gatti RA, Berkel I, Boder E, et al. Localization of an ataxia-telangiectasia gene to chromosome 11q22-23. Nature. 1988;336(6199):577-580. doi:10.1038/336577a0.

73.Silbernagl S, Despopoulos A, Draguhn A. Taschenatlas Physiologie. 9., vollständig überarbeitete Auflage. Stuttgart, New York: Georg Thieme Verlag; 2018.

74.Barzilai A. ATM deficiency and oxidative stress: a new dimension of defective response to DNA damage. DNA Repair (Amst ). 2002;1(1):3-25. doi:10.1016/S1568-7864(01)00007-6.

75.Jackson SP, Bartek J. The DNA-damage response in human biology and disease. Nature. 2009;461(7267):1071-1078. doi:10.1038/nature08467. 
76. Shiloh Y. ATM and related protein kinases: safeguarding genome integrity. Nat Rev Cancer. 2003;3(3):155-168. doi:10.1038/nrc1011.

77.Shiloh Y. The ATM-mediated DNA-damage response: taking shape. 2006.

78. Moses RE. DNA damage processing defects and disease. Annu Rev Genomics Hum Genet. 2001;2:41-68. doi:10.1146/annurev.genom.2.1.41.

79.Burma S, Chen BP, Murphy M, Kurimasa A, Chen DJ. ATM phosphorylates histone H2AX in response to DNA double-strand breaks. J Biol Chem. 2001;276(45):42462-42467. doi:10.1074/jbc.C100466200.

80.van Gent DC, Hoeijmakers JH, Kanaar R. Chromosomal stability and the DNA double-stranded break connection. Nat Rev Genet. 2001;2(3):196-206. doi:10.1038/35056049.

81.Della Latta V, Cecchettini A, Del Ry S, Morales MA. Bleomycin in the setting of lung fibrosis induction: From biological mechanisms to counteractions. Pharmacol Res. 2015;97:122-130. doi:10.1016/j.phrs.2015.04.012.

82.National Center for Biotechnology Information. Bleomycin, CID=5460769. https://pubchem.ncbi.nlm.nih.gov/compound/Bleomycin. Accessed accessed on April 7, 2020.

83.Ranjha L, Howard SM, Cejka P. Main steps in DNA double-strand break repair: an introduction to homologous recombination and related processes. Chromosoma. 2018;127(2):187-214. doi:10.1007/s00412-017-0658-1.

84. Lee J-H, Paull TT. ATM activation by DNA double-strand breaks through the Mre11-Rad50-Nbs1 complex. Science. 2005;308(5721):551-554. doi:10.1126/science.1108297.

85.Lavin MF, Kozlov S. ATM activation and DNA damage response. Cell Cycle. 2007;6(8):931-942. doi:10.4161/cc.6.8.4180. 
86.Bakkenist CJ, Kastan MB. DNA damage activates ATM through intermolecular autophosphorylation and dimer dissociation. Nature. 2003;(421).

87.Derheimer FA, Kastan MB. Multiple roles of ATM in monitoring and maintaining DNA integrity. FEBS Lett. 2010;584(17):3675-3681. doi:10.1016/j.febslet.2010.05.031.

88.Kouzarides T. Chromatin modifications and their function. Cell. 2007;128(4):693-705. doi:10.1016/j.cell.2007.02.005.

89.West MH, Bonner WM. Histone 2A, a heteromorphous family of eight protein species. Biochemistry. 1980;19(14):3238-3245. doi:10.1021/bi00555a022.

90.Tanaka T, Halicka D, Traganos F, Darzynkiewicz Z. Cytometric analysis of DNA damage: phosphorylation of histone $\mathrm{H} 2 \mathrm{AX}$ as a marker of DNA doublestrand breaks (DSBs). Methods Mol Biol. 2009;523:161-168. doi:10.1007/978-1-59745-190-1_11.

91. Guo Z, Kozlov S, Lavin MF, Person MD, Paull TT. ATM activation by oxidative stress. Science. 2010;330(6003):517-521. doi:10.1126/science.1192912.

92.Taylor A, Shang F, Nowell T, Galanty Y, Shiloh Y. Ubiquitination capabilities in response to neocarzinostatin and $\mathrm{H}(2) \mathrm{O}(2)$ stress in cell lines from patients with ataxia-telangiectasia. Oncogene. 2002;21(28):4363-4373. doi:10.1038/sj.onc.1205557.

93. MacNee W. Oxidative stress and lung inflammation in airways disease. Eur $J$ Pharmacol. 2001;429(1-3):195-207. doi:10.1016/S0014-2999(01)01320-6.

94.Sies H. Oxidative stress: oxidants and antioxidants. Exp Physiol. 1997;82(2):291-295. doi:10.1113/expphysiol.1997.sp004024.

95.Santus P, Corsico A, Solidoro P, Braido F, Di Marco F, Scichilone N. Oxidative stress and respiratory system: pharmacological and clinical reappraisal of $\mathrm{N}$ acetylcysteine. COPD. 2014;11(6):705-717. doi:10.3109/15412555.2014.898040. 
96. Reichenbach J, Schubert R, Schindler D, Müller K, Böhles H, Zielen S. Elevated oxidative stress in patients with ataxia telangiectasia. Antioxid Redox Signal. 2002;4(3):465-469. doi:10.1089/15230860260196254.

97.Reichenbach J, Schubert R, Schwan C, Müller K, Böhles HJ, Zielen S. Antioxidative capacity in patients with ataxia telangiectasia. Clin Exp Immunol. 1999;117(3):535-539.

98. Corti M, Brody AR, Harrison $\mathrm{JH}$. Isolation and primary culture of murine alveolar type II cells. Am J Respir Cell Mol Biol. 1996;14(4):309-315. doi:10.1165/ajrcmb.14.4.8600933.

99.Pardo A, Selman M. Lung Fibroblasts, Aging, and Idiopathic Pulmonary Fibrosis. Ann Am Thorac Soc. 2016;13 Suppl 5:S417-S421. doi:10.1513/AnnalsATS.201605-341AW.

100. Harrison JH, Porretta CP, Leming K. Purification of murine pulmonary type II cells for flow cytometric cell cycle analysis. Exp Lung Res. 1995;21(3):407421. doi:10.3109/01902149509023716.

101. Adamson IY, Bowden DH. Bleomycin-induced injury and metaplasia of alveolar type 2 cells. Relationship of cellular responses to drug presence in the lung. Am J Pathol. 1979;96(2):531-544.

102. Kim CFB, Jackson EL, Woolfenden AE, et al. Identification of bronchioalveolar stem cells in normal lung and lung cancer. Cell. 2005;121(6):823-835. doi:10.1016/j.cell.2005.03.032.

103. Adamson IYR, Bowden DH. The Pathogenesis of Bleomycin-Induced Pulmonary Fibrosis in Mice. Am J Pathol. 1974;77(2):185-198.

104. Messier EM, Mason RJ, Kosmider B. Efficient and rapid isolation and purification of mouse alveolar type II epithelial cells. Exp Lung Res. 2012;38(7):363-373. doi:10.3109/01902148.2012.713077. 
105. Demaio L, Tseng W, Balverde Z, et al. Characterization of mouse alveolar epithelial cell monolayers. Am J Physiol Lung Cell Mol Physiol. 2009;296(6):L1051-8. doi:10.1152/ajplung.00021.2009.

106. Rice WR, Conkright JJ, Na C-L, Ikegami M, Shannon JM, Weaver TE. Maintenance of the mouse type II cell phenotype in vitro. Am J Physiol Lung Cell Mol Physiol. 2002;283(2):L256-64. doi:10.1152/ajplung.00302.2001.

107. Cossarizza A, Chang H-D, Radbruch A, et al. Guidelines for the use of flow cytometry and cell sorting in immunological studies (second edition). Eur $J$ Immunol. 2019;49(10):1457-1973. doi:10.1002/eji.201970107.

108. Schubert R, Reichenbach J, Royer N, Pichler M, Zielen S. Spontaneous and oxidative stress-induced programmed cell death in lymphocytes from patients with ataxia telangiectasia (AT). Clin Exp Immunol. 2000;119(1):140147. doi:10.1046/j.1365-2249.2000.01098.x.

109. van Houten $\mathrm{B}$, Woshner $\mathrm{V}$, Santos $\mathrm{JH}$. Role of mitochondrial DNA in toxic responses to oxidative stress. DNA Repair (Amst). 2006;5(2):145-152. doi:10.1016/j.dnarep.2005.03.002.

110. Stagni V, Cirotti C, Barilà D. Ataxia-Telangiectasia Mutated Kinase in the Control of Oxidative Stress, Mitochondria, and Autophagy in Cancer: A Maestro With a Large Orchestra. Front Oncol. 2018;8:73. doi:10.3389/fonc.2018.00073.

111. Valentin-Vega YA, Maclean $\mathrm{KH}$, Tait-Mulder J, et al. Mitochondrial dysfunction in ataxia-telangiectasia. Blood. 2012;119(6):1490-1500. doi:10.1182/blood-2011-08-373639.

112. Ambrose M, Goldstine JV, Gatti RA. Intrinsic mitochondrial dysfunction in ATM-deficient lymphoblastoid cells. Hum Mol Genet. 2007;16(18):2154-2164. doi:10.1093/hmg/ddm166. 
113. Ditch S, Paull TT. The ATM protein kinase and cellular redox signaling: beyond the DNA damage response. Trends Biochem Sci. 2012;37(1):15-22. doi:10.1016/j.tibs.2011.10.002.

114. Tucker MA, Fox BM, Seigler N, et al. Endothelial Dysfunction in Cystic Fibrosis: Role of Oxidative Stress. Oxid Med Cell Longev. 2019;2019:1629638. doi:10.1155/2019/1629638.

115. Galli F, Battistoni A, Gambari R, et al. Oxidative stress and antioxidant therapy in cystic fibrosis. Biochim Biophys Acta. 2012;1822(5):690-713. doi:10.1016/j.bbadis.2011.12.012.

116. Maciejczyk M, Heropolitanska-Pliszka E, Pietrucha B, et al. Antioxidant Defense, Redox Homeostasis, and Oxidative Damage in Children With Ataxia Telangiectasia and Nijmegen Breakage Syndrome. Front Immunol. 2019;10:2322. doi:10.3389/fimmu.2019.02322.

117. Yeo AJ, Fantino E, Czovek D, Wainwright CE, Sly PD, Lavin MF. Loss of ATM in Airway Epithelial Cells Is Associated with Susceptibility to Oxidative Stress. Am J Respir Crit Care Med. 2017;196(3):391-393. doi:10.1164/rccm.201611-2210LE.

118. Reliene R, Fischer $\mathrm{E}$, Schiestl RH. Effect of N-acetyl cysteine on oxidative DNA damage and the frequency of DNA deletions in atm-deficient mice. Cancer Res. 2004;64(15):5148-5153. doi:10.1158/0008-5472.CAN-04-0442.

119. Muraro SP, Souza GF de, Gallo SW, et al. Respiratory Syncytial Virus induces the classical ROS-dependent NETosis through PAD-4 and necroptosis pathways activation. Sci Rep. 2018;8(1):14166. doi:10.1038/s41598-018-32576-y.

120. Adamson IYR. Pulmonary Toxicity of Bleomycin. Environmental Health Perspectives. 1976;(16):119-126.

121. Petukhov D, Richter-Dayan M, Fridlender Z, Breuer R, Wallach-Dayan SB. Increased Regeneration Following Stress-Induced Lung Injury in Bleomycin- 
Treated Chimeric Mice with CD44 Knockout Mesenchymal Cells. Cells. 2019;8(10). doi:10.3390/cells8101211.

122. Della Latta V, Cecchettini A, Del Ry S, Morales MA. Bleomycin in the setting of lung fibrosis induction: From biological mechanisms to counteractions. Pharmacol Res. 2015;97:122-130. doi:10.1016/j.phrs.2015.04.012.

123. Hay J, Shahzeidi S, Laurent G. Mechanisms of bleomycin-induced lung damage. Arch Toxicol. 1991;65(2):81-94. doi:10.1007/bf02034932.

124. Huang T-T, Lai H-C, Ko Y-F, et al. Hirsutella sinensis mycelium attenuates bleomycin-induced pulmonary inflammation and fibrosis in vivo. Sci Rep. 2015;5:15282. doi:10.1038/srep15282.

125. Wallach-Dayan SB, Izbicki G, Cohen PY, Gerstl-Golan R, Fine A, Breuer R. Bleomycin initiates apoptosis of lung epithelial cells by ROS but not by Fas/FasL pathway. Am J Physiol Lung Cell Mol Physiol. 2006;290(4):L790L796. doi:10.1152/ajplung.00300.2004.

126. Lee VY, Schroedl C, Brunelle JK, et al. Bleomycin induces alveolar epithelial cell death through JNK-dependent activation of the mitochondrial death pathway. Am J Physiol Lung Cell Mol Physiol. 2005;289(4):L521-8. doi:10.1152/ajplung.00340.2004.

127. Kasper M, Barth K. Potential contribution of alveolar epithelial type I cells to pulmonary fibrosis. Biosci Rep. 2017;37(6). doi:10.1042/BSR20171301.

128. Sandoval C, Swift M. Treatment of lymphoid malignancies in patients with ataxia-telangiectasia. Med Pediatr Oncol. 1998;31(6):491-497. doi:10.1002/(sici)1096-911x(199812)31:6<491:aid-mpo5>3.0.co;2-b.

129. Taylor AM, Rosney CM, Campbell JB. Unusual sensitivity of ataxia telangiectasia cells to bleomycin. Cancer Res. 1979;39(3):1046-1050. 
130. Aso Y, Yoneda K, Kikkawa Y. Morphologic and biochemical study of pulmonary changes induced by bleomycin in mice. Lab Invest. 1976;35(6):558-568.

131. Kim ST, Lim DS, Canman CE, Kastan MB. Substrate specificities and identification of putative substrates of ATM kinase family members. $J$ Biol Chem. 1999;274(53):37538-37543.

132. O'Neill T, Dwyer AJ, Ziv Y, et al. Utilization of oriented peptide libraries to identify substrate motifs selected by ATM. J Biol Chem. 2000;275(30):2271922727. doi:10.1074/jbc.M001002200.

133. Allio T, Preston RJ. Increased sensitivity to chromatid aberration induction by bleomycin and neocarzinostatin results from alterations in a DNA damage response pathway. Mutation Research/Fundamental and Molecular Mechanisms of Mutagenesis. 2000;453(1):5-15. doi:10.1016/S00275107(00)00030-0. 


\section{Danksagung}

Für die gute Betreuung und Bereitstellung dieses interessanten Promotionsthemas möchte ich mich zuallererst bei meinem Doktorvater Herrn Prof. Dr. Ralf Schubert bedanken.

Zudem möchte ich einen besonderen Dank an Frau Dr. Ruth Pia Dücker aussprechen, die mich sowohl bei der Durchführung der Experimente als auch bei der Anfertigung der Dissertationsschrift tatkräftig unterstützt hat und immer ein offenes Ohr für mich hatte. Weiterhin gilt ein großes Dankeschön dem gesamten pneumologisch-immunologischen Laborteam für die Hilfe bei den grundlegenden Laborarbeiten, der Entnahme der Lungenproben sowie den offenen Ohren und motivierenden Worten während der vielen Kaffeepausen.

Ein besonderer Dank geht an dieser Stelle an meine Familie, die mich in der Zeit meines Studiums und der Fertigstellung der Promotion sowie in meiner bisherigen beruflichen Laufbahn immer unterstützt und zur Seite gestanden haben. 
Lebenslauf 
schriftliche Erklärung 